\title{
SENTENCE PATTERN AND USAGE IN NIGERIA'S 2015 PRESIDENTIAL DEBATE
}

Roseline Abonego Adejare

Department of Language, Arts and Social Science Education, Lagos State University, PMB 0001, LASU Post Office, Badagry Expressway, Ojo, Lagos, Nigeria

Corresponding Author: Roseline Abonego Adejare, E-mail: abonego@yahoo.com

\section{ARTICLE INFO}

Article history

Received: March 08, 2018

Accepted: June 29, 2018

Published: August 31, 2018

Volume: 9 Issue: 4

Advance access: July 2018

Conflicts of interest: None

Funding: None

\section{Key words:}

Sentence Pattern,

Major Sentence,

Minor Sentence,

Simple Sentence,

Compound Sentence,

Complex Sentence,

Clause Structure,

Rankshifted Clause

\section{ABSTRACT}

This study of sentence pattern and usage in Nigeria's 2015 Presidential Debate identifies and accounts for all occurring major and minor sentences, classifies the major sentences into simple, compound and complex subtypes, determines their typological and thematic distribution, and demonstrates how they were strategically employed to articulate each debater's points. The data comprises 1876 sentences and was analysed using an improved version of the systemic grammatical model. Results show that major and minor sentences represent 92 and 8 per cent respectively and that while the simple sentence accounted for 77 per cent, compound and complex sentences make up 10 and 13 per cent respectively. Mean length of sentence was 13.6 words and clause density in respect of compound and complex sentences was 1.6 and 2.22 per sentence. Of the seventeen variants of the simple sentence isolated 21 per cent had their elements of structure realised by rankshifted clauses while 20 per cent were affected by multiplicity, mobility and inversion. Though the rest 59 per cent were kernel sentences of the basic SPCA structural pattern, it was not uncommon to find structurally complex groups as elements of clause structure. What determined which of alpha or beta was clause-initially was the focus of the message conveyed. So thematic fronting is not limited to the single clause sentence. Sentence length and type, positioning of clauses or parts thereof, and decisions on conjunctions and finite or non-finite clauses, were greatly governed by theme and the speaker's mediate goals and grammatical sophistication. These are proofs of the strategic use of the sentence by politicians.

\section{INTRODUCTION}

The initial motivation for this study came from a recently concluded one on the central pronouns in Nigeria's 2015 Presidential Debate (Adejare, 2018). While working on that paper it struck me that the twenty-three odd pronouns with a combined frequency of 2409 could not have been effective on their own in coding debaters' responses outside the wider context of the sentences in which they functioned. The focus then was on the strands, or, indeed, part thereof, that make up the whole. In the current study attention is paid to the whole itself, the syntactic unit sentence. A second factor is the revelation, following a critical examination of existing literature on political texts, of a paucity of studies specifically devoted to syntactic structure generally and the sentence particularly. What exist are occasional references that are excusably fragmentary and shallow because that is not their focus (cf. Ayeomoni, 2001; Opeibi, 2010; Bellova 2012; van Leeuwen 2012). This study is therefore holistic. It is concerned with how the largest grammatical unit syntactic patterns' formal and functional manifestations were employed to achieve debaters' goals. The sentence in political texts is not known to have been comprehensively analysed as envisaged in this study, whereas politicians have been known to exploit syntactic structures to a great personal advantage (van Dijk 1979).

This study therefore takes the grammatical analysis of political texts one step further by examining how the sentence and its formal and functional features were used to achieve debaters' goals in Nigeria's 2015 Presidential Debate. It aims specifically to identify and formally account for all occurring sentences in the corpus using the major/minor sentence dichotomy, classify all the major sentences into the structural subtypes of simple, compound and complex, determine the frequency of occurrence and thematic distribution of each structural type and subtype, and demonstrate how debaters strategically employed the different sentence types and patterns to articulate their policies and subsequently actualise their goals of convincing the electorate to vote for them. It is hoped that its outcome will fill some of the existing gaps in the syntax of political texts and stimulate further research on the subject. 


\section{REVIEW OF LITERATURE}

\section{Previous Studies}

Millar and Curie (1972) reveal that the normal SPCA pattern of the English clause structure can indeed be varied for the purpose of achieving rhyme in poetry and for particular effects in prose. On prose, they particularly demonstrate that the complement can be moved to initial position for emphasis, the subject and complement can be inverted in order to provide logical connection between two sentences or even paragraphs, the adjunct can be transferred from sentence end to execute both thematic and structural functions, and, where it is a single adverb, its positioning can alter the rhythm of the sentence with implications for meaning. Furthermore, they provide textual examples to show that alterations in the normal ordering of the elements of clause structure, including subject-predicator inversion, have a controlling effect on the reader/listener's attitude towards the rest of the clause. Although the current study is neither based on spoken prose nor prose as it is generally known, it will nevertheless benefit from these insights.

In his paper articulating the subject political discourse van Dijk (1979: 37) states that syntactic style can be politically manipulated but in more subtle and less obvious manner compared to lexical style and points out that variations of word order, the choice of specific syntactic categories, pronouns, clause embedding, and sentence complexity etc. are used to express underlying meanings in sentence structures. Wilson (2005:402) similarly highlights three ways in which syntax impact political texts as using specific syntactic transformations, employing relatively uncontroversial structural selections such as the use of nominalised clauses to cause attention to be shifted away from what is not desired, and the relative distribution of particular syntactic selections such as negation. Van Leeuwen (2012) adopts a stylistics approach to the analysis of political texts consisting of a check-list of four categories, namely lexical, grammatical, figures of speech, and context and cohesion. What is of interest here, which makes the present study all the more compelling, is his decision not to focus on the grammatical because it is the relatively infrequently analysed category in political texts. However, to demonstrate the importance of grammatical phenomena and show that complementation can add to the inventory of linguistic tools relevant to Critical Discourse Analysis (CDA), van Leeuwen compares Geert Wilder's 2007 speech contributing to the debate on 'Islamic Activism' with Vogelaar's. He reveals an average sentence length of 15.4 and 19.8 words per sentence $(\mathrm{w} / \mathrm{s})$ respectively and adds that where complementation constructions are present, they have rhetorical effects that enable the speaker to describe their viewpoint as their perspective, leaving room for discussion and negotiation, and that where complementation constructions are lacking, however, ideas are primarily presented as facts, leaving minimal room for negotiation and discussion. These go to show how syntactic simplicity or complexity impact political texts.

Cienki (2009:8-9) compares two US vice presidential candidates' use of spoken language framing devices in the 2008 debate and reports that while Biden's argument structures conformed more to written discourse than to spoken language because of multiple embedding of clauses, Palin's syntax was characterised by simplicity as short sentences interlaced with repetition in a 'chant-like' manner to achieve logical connection between ideas. Bellova (2012) analyses political crisis speeches of ten American presidents at the syntactic, semantic and pragmatic levels and concludes that war discourse syntax is getting simpler with the sentences getting shorter and less complex. A mean length of sentence of 21,16 , and $20 \mathrm{w} / \mathrm{s}$ was recorded for Obama, Bush, and Reagan as opposed to the 29, 39, and 35 for Lincoln, McKinley, and Wilson respectively. There was an even distribution of coordinated and subordinated sentences in Obama's speech whereas Reagan's was predominantly coordinated; and, while Truman's sentences lacked 'syntactic sophistication and complexity' due to the absence of inversion, finite clauses, and appositive phrases etc. which make discourse advanced, Roosevelt produced 'powerful' sentences with reversed word order

The only syntax-related analysis in Astrero's (2017) CDA study aimed at identifying the personal pronouns, modals and mood of the sentences is the sparse information on the $89.47,10.53$, and 0 per cent proportion respectively of declarative, subjunctive and imperative mood in the corpus. Similarly, Abdel-Moety's (2015:5) observation that (Hillary) 'Clinton's language, is in general, not simple. Her sentences are long. Most of her sentences tend to be compound or complex rather than simple' is the only syntax-related statement in a work that fails to state the number and type of sentences produced possibly because the focus was on transitivity, modality and textual analysis. In Akinwotu's (2013) Speech Act analysis of acceptance of nomination speeches, no grammatical analysis of the eighteen extracts examined was undertaken. Finally, based on the title of Kenzhekanova's (2015) article one expects to find emerge from some form of analysis a list of linguistic features (including syntactic) that characterise political texts, but none can be pinpointed.

The foregoing reveals the absence of a rigorous analysis of the sentence and of syntactic structure in political texts aimed at their characterisation, which provides further justification for the current research effort.

\section{Theoretical Framework}

This work is predicated upon an enhanced systemic grammatical theory because it provides the best framework that can be improved to more accurately analyse the syntax of the Presidential Debate texts. An off-shoot of Firthian integrationist functionalism, Systemic Grammar (SG) is concerned with the discovery of the nature and structure of linguistic form and its functional properties. As a rule functionalists generally describe linguistic data in relation to its various functions at both the formal and textual levels. Systemic Grammar thus studies language as part of the social process and argues that it is the external relations between a language and the individual user or community that gives linguistic signs their shape and makes them recognisable in the first instance. It gives prominence to both meaning and context (Firth 1951; Halliday 1961, 1985; Berry 1975; Halliday \& Matthiessen 2004), 
and insists on an intrinsic integration of linguistic signs with their functions which generate formal meanings and therefore enables one to theoretically deal with language as a form of human behaviour (Harris 1990). Consequently, SG accounts for more elements of natural language than other models and is therefore able to account for more formal functions.

Systemic Grammar correctly recognises form and situation as the two primary elements of language structure, but following Saussure (1916) it claims that situation is not part of linguistics (cf. Halliday et.al., 1964:18). The absence of situation creates descriptive limitations, such as the lack of capacity to more accurately analyse the formal element of language beyond the clause. This study is based on the fact that form and situation are the primary elements of language structure and that both determine the structure of a text's form in language use. The primary function of language is text message coding, where the message of an encoder to a decoder determines a text's thesis, code (actual grammatical forms in a text), culture and date, all of which manifest in a text's actual form such as the Presidential Debate data here (cf. Adejare,0., forthcoming). This work examines the occurrence of syntactic structure in a particular variety of language use; it is concerned with discovering the underlying grammatical form of the sentence used in political texts. An improved version of the systemic grammatical theory will therefore more adequately handle the data.

\section{Grammatical Model}

Because SG has the most accurate clause structure formula (S) P (C) (A) (Halliday (1961; Halliday et al. 1964), it is better suited to the problem of handling new data (Coulthard \& Montgomery, 1985:7), theoretically fuller and more coherent (Butler, 1979:72), and therefore gives a clearer and fuller account of grammatical form and function. The newer model Systemic Functional Grammar (SFG) is theoretically formulated to solve the problem of 'texts' (Halliday 1966, 1970, 1985; Morley 1985; Bloor \& Bloor, 1990; Halliday \& Matthiessen 2004; Eggins 2004), which is still being grappled with (Halliday \&Webster 2008) and which lies outside the scope of this study. Not only does SFG not recognise the grammatical unit sentence, it has replaced it with 'clause complex' and consigned it to written language (Halliday, 1985:192-193). The notion of 'clause complex' cannot permit a full account to be made of all sentence types outside 'simple'. In his 1988 review of Halliday's An introduction to functional grammar, Huddleston notes that 'the shortcomings of rank-based constituency are indeed more apparent in the current functional grammar than in the original scale-and-category model' (p141), the 'multi-dimensional analysis' of the clause (textual, interpersonal and ideational) does not satisfactorily describe its grammatical properties (p157) and that the lack 'of clear grammatical criteria will make the analysis difficult to apply'.(p173). It is our strong conviction that the adequacy of a linguistic model lies not in its name or philosophical claims or age but in its ability to describe natural language most accurately and most efficaciously. The earlier version is therefore the grammatical model chosen.
Because of the limitation noted above, while SG's syntactic description is the most accurate among its rivals, it requires improvement to adequately account for the syntax of language use data. The largest syntactic unit is the sentence which is made up of one or more clauses. A clause is made up of one or more groups and a group is made up of one or more words. The word is made up of one or more morphemes. That a sentence is made up of one or more clauses generates three types of sentences - a simple sentence made up of one alpha (independent) clause, a compound sentence made up of more than one alpha clause, and a complex sentence made up of at least one alpha clause and one beta (dependent) clause. The clause is therefore the primary element of sentence structure. Whereas the alpha clause is obligatory, the beta clause is optional. The structure of the sentence is represented formulaically as $\mathrm{S}\left(\beta^{0-\mathrm{n}}\right) \alpha^{1-\mathrm{n}}\left(\beta^{0-\mathrm{n}}\right)$. Based on its function in texts, major and minor sentence types are also recognised. The major sentence is that clause with a predicator as an obligatory element of structure, while the minor sentence, also called verbless clause (Quirk et al. 1985: 996997), is that clause that lacks a predicator (cf. Adejare \& Adejare, 2006: 49-67; 94-96).

Of all the existing clause structure formulas SG's four-element $(\mathrm{S}) \mathrm{P}(\mathrm{C})(\mathrm{A})$ is the most accurate as earlier stated. But the situation functions of language (Adejare \& Adejare, 2006: 86-92) create varieties of clause structures in texts outside the $(\mathrm{S}) \mathrm{P}(\mathrm{C})(\mathrm{A})$ formula. For instance, while it generates declarative clauses such as $\| \operatorname{Jim} \mid$ gave| a smile.\|, it can neither generate the interrogative clause || $\operatorname{Did}|\operatorname{Jim}|$ give a smile? || nor clauses involving stylistically motivated inversion such as $\|$ Inside the room |was |Jim $\mid$. Besides, both complements and adjuncts may be multiple in a sentence, e.g.,.,.,. $\|$ Jim $\mid$ gave| you $\mid$ a smile $\|$ and ||Jim |gave| you| a smile $\mid$ covetously| yesterday. || The adjunct is so mobile that it can occur before and in-between other structural elements, e.g.,.,... ||Covetously,| Jim |gave| you | a smile| yesterday \|, || Jim |covetously |gave |you |a smile| yesterday.||, and ||Jim $\mid$ didn't $\mid$ covetously| give | you| a smile| yesterday || .

Thus, apart from recognising simple, compound and complex sentences as well as major/minor sentences, I will recognise multiplicity, mobility and inversion of some clause structure elements in the data coded by politicians. I will ignore the situation-induced moves among the moderators who asked the questions that each candidate answered because they have no major impact on the syntactic forms of the answers to the questions.

\section{METHOD}

\section{Data Base}

The text of the transcript of the 2015 Presidential Debate is the data base for this study. It was downloaded using https:// youtu.be/MGwkZr3.

\section{The Debaters}

Twelve flag-bearers of twelve political parties participated in the two-session presidential debate, namely Tunde 
Anifowoshe Kelani (Action Alliance: AA), Alhaji Ganiyu O. Galadima (Allied Congress Party of Nigeria: ACPN), Rafiu Salau (Alliance for Democracy: AD),Dr Mani Ibrahim Ahmed (African Democratic Congress: ADC), Adebayo Musa Ayeni (African People's Alliance: APA), Chief Sam Ekeh, $P h$. $D$ (Citizens Popular Party: CPP), Chief Ambrose Albert Owuru (Hope Democratic Party: HDP), Professor Comfort Oluremi Sonaiya (KOWA Party: KOWA), Chief Martin Onovo (National Conscience Party: NCP), Dr Goodluck Ebele Jonathan (Peoples Democratic Party: PDP), Chief Godson Mgboli Okoye (United Democratic Party: UDP), and Chief Chekwas Okorie (United Progressive Party: UDP). Subsequent in-text references to the debaters are on party acronym basis.

\section{The Questions}

The questions responded to covered eight themes as listed below (Each debater had three minutes to respond to each question and one to round off):

Q1 (Motivation): 'Why do you want to be president of Nigeria?'

Q2 (Power): What do you intend to do (.) to guarantee steady power supply in Nigeria?'

Q3 (Oil): 'How do you intend to tackle the problem of (.) oil theft?'

Q4 (Corruption): 'What will be your template for tackling corruption?'

Q5 (Security):'What strategic policy direction would you put in place to guarantee the security or safety of life and property of Nigerians, to rehabilitate the victims of insurgency in the North East, reconstruct the zone and eventually bringing back the Chibok girls?'

Q6 (Education): 'What are your immediate and long-term plans to restore dignity to our education?'

Q7 (Agriculture): 'What specific plans do you have (.) to address the issue of agriculture in

such a way that it will be useful to industries and also bring money into the pockets of our people?'

Q8: Round off

\section{Problems}

The downloaded text of the transcript of the 2015 Presidential Debate was listened to several times to get familiar with its contents. It was discovered that some sections either ended abruptly or began midstream. Five questions were affected (cf. Table 4 below).

\section{The Corpus}

The material was carefully transcribed orthographically and the number of words spoken by each debater in response to each question was manually counted. Questions $1-8$ yielded 4876, $2490,5168,4549,3180,2298,2123$, and 785 words respectively. These totalled 25469 words, which is the corpus size.

\section{Data Collection}

The 25 469-word corpus was carefully studied to identify and mark all the sentences therein. Again, these were manually counted and recorded for each debater and for each question. Altogether there occurred 1876 sentences, and this constitutes the data for the study.

\section{Procedure for Data Analysis}

The analysis of data was in two phases. Major sentences were identified and classified into the three structural types of simple, compound and complex and the frequency of each type was determined. Further analyses at more delicate levels were undertaken. For example, each identified simple sentence was critically examined to ascertain whether or not the optional elements of clause structure were realised by rankshifted clauses, or whether or not the situation-induced features of multiplicity, mobility and inversion that radically alter the structure of the English clause were at play. Seventeen variants were identified and the frequency of each one was determined according to themes and according to debaters. Next, the structurally compound sentence was examined to identify the number of alpha clauses therein. The same was done for the structurally complex sentence, with focus on whether the beta clause was finite or non-finite. As with the simple sentence the frequency of each variant of the compound and complex sentences was also determined. The minor sentences were similarly identified and dichotomised in terms of presence or absence of the verbal group (VBG). Since each compound and complex sentence minimally has two clauses, it became expedient to numerically ascertain their clause constituents and add same to those of simple sentence and minor sentence to generate the total number of clauses and also account for the data from the perspective of the clause.

The second phase of the analysis of data entailed a critical examination of the corpus to find out precisely how each identified sentence type or subtype was used to respond to the questions posed in terms of recognising the problem and justifying the thesis (R), specifying actions to be taken and justifying same (S), and concluding the submissions (C). To achieve this, each sentence type was first listed, followed by examples reflecting all the twelve debaters and all the eight themes as applicable. Samples of these are presented and discussed to demonstrate how they aided debaters to realise their goals.

\section{PRESENTATION AND DISCUSSION OF RESULTS}

\section{Preliminary Remarks}

The 1876 sentences comprise 1729 major and 147 minor types distributed as Table 1 displays.

From the facts displayed in Table 1 it can be seen that major sentences were dominant. But that is how far the comparison between major and minor sentences and indeed among the other variables can go. It cannot be validly stated, for instance, with the figures recorded for them, that UDP generated the highest number of sentences and ADC the least, because of the factors already hinted at above, which is more vividly captured by the empty cells in Table 4 below (Notice that only in Q1, Q3 and Q4 were all twelve debaters' responses fully recoverable). 
To make meaningful comparison possible, the solution sought was to calculate the average length of sentence relative to the number of words generated by each debater and this yielded fruits. Since there were 1876 sentences in all and the corpus size is 25469 words, the mean length of sentence was calculated as $13.6 \mathrm{w} / \mathrm{s}$. Five debaters recorded mean length of sentence above the group mean, six recorded below the group mean while one (PDP) posted the same mean sentence length as the group average. The highest was $20.03 \mathrm{w} / \mathrm{s}$ while the lowest was $9.85 \mathrm{w} / \mathrm{s}$ and these were recorded for ADC and HDP respectively. Table 2 exposes these and more facts.

These figures contrast sharply with what Bellova (2012) reported. Her subjects' sentences were by far longer, as only five debaters' mean sentence length is anywhere near the lowest. While difference in period may explain the disparity (Only Obama and Bush belong in the twenty-first century), a more logical explanation may lie in genre difference: The presidents' speeches are samples of spoken prose whereas the debaters' represent spontaneous speech.
All the 1729 major sentences were classified into types. As Table 3 below shows, the structurally simple sentence was dominant, accounting for 77 per cent. It was distantly followed by the structurally complex sentence. The compound sentence was the least recurring.

The 1729 major sentences bore 2103 major clauses made up of 1330 clauses from the same number of simple sentences, 261 from compound sentences, and 512 from complex sentences. This gives an average of 1.22 clauses per major sentence. However, it was 1.6 and 2.22 clauses per sentence respectively of compound and complex sentences. In essence, clause density was much higher with the complex sentence than with the compound sentence. Because the structurally simple sentence bears a single alpha clause only and the minor sentence is technically less sentence due to its partial realisation of elements of clause structure caused by natural language dynamism, the issue of clause density does not apply to these two categories. But, a slight difference was recorded when the 147 clauses from the same number of minor sentences were added to

Table 1. Typological Distribution of Sentences

\begin{tabular}{|c|c|c|c|c|c|c|c|c|c|c|c|c|c|}
\hline \multirow[t]{2}{*}{ Types } & \multicolumn{13}{|c|}{ Debaters } \\
\hline & $\mathbf{A A}$ & AD & ADC & APA & ACPN & CPP & HDP & KOWA & PDP & UDP & UPP & Total & $\%$ \\
\hline Major & 143 & 76 & 69 & 102 & 91 & 180 & 125 & 215 & 224 & 230 & 155 & 1729 & 92 \\
\hline Minor & 31 & 4 & 3 & 2 & 7 & 8 & 9 & 27 & 20 & 24 & 8 & 147 & 8 \\
\hline Total & 174 & 80 & 72 & 111 & 98 & 188 & 134 & 242 & 244 & 254 & 163 & 1876 & \\
\hline
\end{tabular}

Table 2. Average Length of Sentence

\begin{tabular}{lccc}
\hline Debaters & Words produced & Sentences produced & Mean length of sentence (w/s) \\
\hline AA & 1749 & 174 & 10.1 \\
ACPN & 1474 & 111 & 13.3 \\
AD & 1195 & 80 & 15 \\
ADC & 1442 & 72 & 20.03 \\
APA & 1866 & 106 & 17.6 \\
CPP & 1935 & 98 & 19.7 \\
HDP & 1851 & 188 & 9.85 \\
KOWA & 1991 & 134 & 14.9 \\
NCP & 2743 & 242 & 11.32 \\
PDP & 3313 & 244 & 13.6 \\
UDP & 3110 & 254 & 12.2 \\
UPP & 2800 & 163 & 17.2 \\
Total & 25.469 & 1876 & 13.6 \\
\hline
\end{tabular}

Table 3. Typological Distribution of Major Sentences

\begin{tabular}{|c|c|c|c|c|c|c|c|c|c|c|c|c|c|c|}
\hline \multirow[t]{2}{*}{ Types } & \multicolumn{14}{|c|}{ Debaters } \\
\hline & $\mathbf{A A}$ & AD & ADC & APA & ACPN & CPP & HDP & KOWA & NCP & PDP & UDP & UPP & Total & $\%$ \\
\hline Simple & 121 & 06 & 52 & 72 & 91 & 66 & 156 & 103 & 160 & 151 & 181 & 117 & 1330 & 77 \\
\hline Compound & 9 & 7 & 7 & 19 & 4 & 8 & 10 & 11 & 18 & 33 & 18 & 24 & 168 & 10 \\
\hline Complex & 13 & 9 & 10 & 11 & 14 & 27 & 14 & 11 & 37 & 40 & 31 & 14 & 231 & 13 \\
\hline Total & 143 & 76 & 69 & 102 & 109 & 91 & 180 & 125 & 215 & 224 & 230 & 155 & 1729 & \\
\hline
\end{tabular}


give 2250 clauses in all. The average number of clauses per sentence became 1.2. From the perspective of the data there thus occurred 2103 major clauses representing 93.5 per cent and 147 minor clauses constituting 6.53 per cent. The proportion of major clauses relative to minor was much higher than the $82 \mathrm{v} 18$ reported in respect of spoken instructional texts (Adejare, 2013).

At this juncture it is important to state that forty-three sentences representing 2.5 per cent of major sentence realisations were syntactically defective. They comprise six simple and thirty-seven complex types and are handled separately under collapsed sentences below. Further results are presented and discussed under the headings simple sentence, compound sentence, complex sentence, and minor sentence in that sequence. Features characterising the sentence in political texts are highlighted as concluding remarks.

\section{The Simple Sentence}

Table 4 below shows the distribution of the simple sentence according to themes and according to debaters. It gives a clear picture of the number of simple sentences produced and what each of the twelve debaters and eight themes actually contributed to the pool.

The empty cells earlier referred to notwithstanding, it is not difficult to see that Q3 had the highest number of simple sentences out of the three questions for which recovery of the text of the transcript was full and that the number of simple sentences not only varied according to theme but also differed according the individual debater. To determine each theme's average number of simple sentences the total recorded for them was divided by the number of debaters involved. The outcome shows that Q3 had the highest concentration of the structurally simple sentence (24) while Q8, where debaters were allowed only one minute as opposed to the three of Q1-Q7, record- ed the lowest (7.8). A similar computation done for the debaters reveals that HDP had the highest average (31.2) while ADC posted the lowest (13). The overall mean for debaters was 110 and for themes 166.3.These are clear indications of marked differences in the frequency of simple sentence occurrence occasioned by differences in themes and debaters. The absence of precedence makes comparison somewhat difficult, though. For instance, Cienki's (2009) report on Palin's syntax lacks supporting statistics.

Because of its little analytical value calculating length of sentence for the simple sentence was not pursued. Attention was consequently shifted to how each simple sentence faired syntactically and the outcome is detailed in Table 5 .

As Table 5 displays, the 1330 structurally simple sentences were sorted into seventeen subtypes according to syntactic potentialities. Those not manifesting rankshifted clauses as primary elements of structure featured the most. Let us call them kernel sentences. They were distantly followed by those with rankshifted clauses as complement or as adjunct, adjuncts at initial position, subject-predicator inversion, and multiple adjuncts in that order. No instance of the simple sentence with the rankshifted clause as subject, complement and adjunct, or as subject and adjunct, was seen.

The seventeen syntactic variants were grouped into five based on realisation thus: the kernel sentence, the rankshifted clause as an element of structure, multiplicity of the complement and adjunct, mobility of the adjunct, and inversion of clausal elements. Indeed, with the notable exception of the kernel sentence, most others exhibited more than one feature. The pragmatic decision taken in such circumstances was to determine the syntactically more dominant feature and assign the given sentence accordingly. An instance is (14a) below, which could have easily fallen under the rankshifted clause as subject and adjunct but which was

Table 4. Thematic distribution of the simple sentence

\begin{tabular}{|c|c|c|c|c|c|c|c|c|c|c|}
\hline \multirow[t]{2}{*}{ Debaters } & \multicolumn{10}{|c|}{ Themes/Questions } \\
\hline & Q1 & Q2 & Q3 & Q4 & Q5 & Q6 & Q7 & Q8 & Total & Mean \\
\hline $\mathrm{AA}$ & 24 & 23 & 39 & 25 & - & - & - & & 121 & 30.3 \\
\hline $\mathrm{ACPN}$ & 27 & 21 & 29 & 14 & - & - & - & & 91 & 22.8 \\
\hline $\mathrm{AD}$ & 17 & 14 & 20 & 18 & - & - & - & & 60 & 15 \\
\hline $\mathrm{ADC}$ & 20 & 13 & 9 & 9 & - & - & - & & 52 & 13 \\
\hline APA & 21 & 14 & 10 & 16 & 12 & - & - & & 72 & 14.4 \\
\hline $\mathrm{CCP}$ & 12 & 22 & 14 & 8 & 18 & - & - & & 66 & 13.2 \\
\hline HDP & 37 & - & 39 & 48 & 10 & - & - & & 156 & 31.2 \\
\hline KOWA & 15 & - & 15 & 16 & 15 & 18 & 13 & 11 & 103 & 14.7 \\
\hline $\mathrm{NCP}$ & 25 & - & 41 & 21 & 22 & 25 & 19 & 7 & 160 & 22.8 \\
\hline PDP & 20 & - & 20 & 27 & 31 & 20 & 22 & 11 & 151 & 21.9 \\
\hline UDP & 24 & - & 32 & 33 & 37 & 39 & 18 & 6 & 181 & 26.9 \\
\hline UPP & 24 & - & 20 & 14 & 24 & 15 & 16 & 4 & 117 & 16.7 \\
\hline Total & 266 & 122 & 288 & 249 & 170 & 106 & 88 & 39 & 1330 & 111 \\
\hline Mean & 22.2 & 17.3 & 24 & 20.8 & 21.3 & 21.2 & 17.6 & 7.8 & 166.3 & \\
\hline
\end{tabular}


classified as subject only because of the dominance of the $\mathrm{x}+\mathrm{g}$ non-finite $\mathrm{VBG}$ clause.

The presentation that follows takes each category at a time. The symbol or acronym adopted for each structural variant under consideration as displayed in Table 5 is placed after its appropriate heading for ease of recognition. Textual examples are provided and analysed, with the debater (e.g.,.,.,. AA), theme (e.g.,.,.,. Q1), and context or function ( $\mathrm{R}, \mathrm{S}$ and $\mathrm{C}$ for recognising, specifying, and concluding respectively) enclosed in brackets after each citation. Where necessary, the item under focus is italicised. Comments on how debaters' goals were achieved and on variations in meaning occasioned by changes in syntactic structure and context of use are made. This is done for compound, complex, minor, and collapsed sentences as well.

\section{The Kernel Sentence ([[-]])}

The kernel sentence devoid of rankshifting at the primary degree of delicacy and unaffected by multiplicity, mobility and inversion of clause structure elements recurred 783 times (59 per cent) as already stated. The computed average of kernel sentences per theme per debater is listed in descending order thus: 19.2 (HDP), 17.3 (AA), 15 (NCP), 14.9 (UDP), 14(ACPN), 13.9 (PDP), 11.2 (CPP), 10, (UPP), 8.3 (KOWA), 7.8, (ADC), and 4.8 (AD). Thus kernel sentences were highest produced by HDP and least used by AD.

Eight structural variants of the kernel sentence are derivable from the $(\mathrm{S}) \mathrm{P}(\mathrm{C})(\mathrm{A})$ clause structure formula, but $\|\mathrm{P}\|$ and $\|\mathrm{P} \mid \mathrm{A}\|$ were not seen and $\|\mathrm{P} \mid \mathrm{C}\|$ and $\|\mathrm{P}|\mathrm{C}| \mathrm{A}\|$ were rare outside the context of expressing gratitude as in (1a)-(1b). These are indications that imperative clauses expressing order as an underlying semantic function, as in (1c), were uncommon, which tends to confirm Astrero's (2017) 0 per cent finding.

$$
\begin{array}{lllll}
P & \mathrm{C} & \mathrm{P} & \mathrm{C} & \mathrm{A}
\end{array}
$$

(1a)||Thank |you.||(CPP Q1 C) (1b)||Thank |you | very much.||(AA Q1 R)

$$
\mathrm{P} \quad \mathrm{C} \quad \mathrm{A}
$$

(1c)||Take |the education sector, |for instance.||(PDP Q1 S)

The paucity of imperative clauses means that nearly all the kernel sentences produced were functionally declarative and so occurred with subjects, complements and/or adjuncts. However, examples of the $\|\mathrm{S} \mid \mathrm{P}\|$ type like (2a)-(2b) were hard to come by.

$$
\begin{array}{llll}
+ & \mathrm{S} & \mathrm{P} & \mathrm{P}
\end{array}
$$

(2a)||And |stones |will be thrown.|| (2b)||Questions |will be asked.||(UPP Q1 S)

Not only are (2a)-(2b) agentless passives focussing on the subjects, they were preceded by their respective active voice counterparts: || In a UPP government |we| shall throw | stones.|| and ||We |will ask| questions| in UPP government.||, which are themselves structurally $\|\mathrm{A}|\mathrm{S}| \mathrm{P} \mid \mathrm{C}\|$ and $|\mathrm{S}| \mathrm{P}|\mathrm{C}| \mathrm{A} \|$ and which provide contextual clues for the executor of the actions specified. A non-passive kernel sentence with the || $\mathrm{S} \mid$ $\mathrm{P} \|$ structure is marked in (3).

(3)|| I| used to give| armed robbery |as an example.|| ||We have been killing |armed robbers $\|$.

||Armed robbery |continues.|| ||That |is |enforcement.||(PDP Q4 S)

In effect, $\|\mathrm{S}|\mathrm{P}| \mathrm{C}\|,\|\mathrm{S}|\mathrm{P}| \mathrm{A}\|$ and $\|\mathrm{S} \mathrm{P}|\mathrm{C}| \mathrm{A}\|$ were the most productive. Sample $\|\mathrm{S}|\mathrm{P}| \mathrm{C}\|$ sentences are analysed as (4a)-

\begin{tabular}{|c|c|c|c|c|c|c|c|c|c|c|c|c|c|}
\hline \multirow[t]{2}{*}{ Variants } & \multicolumn{13}{|c|}{ Debaters } \\
\hline & $\mathbf{A A}$ & ACPN & AD & ADC & CPP & HDP & KOWA & NCP & PDP & UDP & UPP & Total & $\%$ \\
\hline$[[-]]$ & 69 & 56 & 19 & 31 & 40 & 98 & 58 & 104 & 97 & 104 & 71 & 783 & 59 \\
\hline$[[\mathrm{S}]]$ & 0 & 2 & 2 & 1 & 1 & 1 & 1 & 1 & 1 & 1 & 2 & 13 & 1 \\
\hline$[[\mathrm{C}]]$ & 10 & 7 & 13 & 6 & 1 & 28 & 14 & 16 & 17 & 21 & 14 & 159 & 12 \\
\hline$[[\mathrm{A}]]$ & 9 & 5 & 8 & 2 & 8 & 6 & 12 & 3 & 6 & 12 & 11 & 94 & 7 \\
\hline$[[\mathrm{S} \& \mathrm{C}]]$ & 0 & 1 & 1 & 0 & 0 & 1 & 3 & 1 & 1 & 1 & 0 & 10 & 0.8 \\
\hline$[[\mathrm{S} \& \mathrm{~A}]]$ & 0 & 0 & 0 & 0 & 0 & 0 & 0 & 0 & 0 & 0 & 0 & 0 & 0 \\
\hline$[[\mathrm{C} \& \mathrm{~A}]]$ & 0 & 0 & 0 & 0 & 0 & 0 & 1 & 0 & 0 & 1 & 1 & 4 & 0.3 \\
\hline$[[\mathrm{S}, \mathrm{C} \& \mathrm{~A}]]$ & 0 & 0 & 0 & 0 & 0 & 0 & 0 & 0 & 0 & 0 & 0 & 0 & 0 \\
\hline Initial C & 0 & 0 & 0 & 0 & 0 & 0 & 0 & 1 & 0 & 0 & 0 & 1 & 0.08 \\
\hline Initial A & 0 & 6 & 8 & 4 & 5 & 5 & 3 & 17 & 9 & 12 & 6 & 82 & 6.2 \\
\hline$A$ after $S$ & 5 & 0 & 0 & 2 & 1 & 1 & 2 & 0 & 2 & 4 & 0 & 15 & 1.13 \\
\hline A before $\mathrm{C}$ & 1 & 0 & 0 & 0 & 0 & 1 & 0 & 1 & 0 & 0 & 0 & 2 & 0.2 \\
\hline Median A & 0 & 3 & 5 & 3 & 0 & 3 & 2 & 2 & 4 & 3 & 1 & 32 & 2.4 \\
\hline Multi-A & 4 & 5 & 2 & 3 & 2 & 2 & 3 & 2 & 7 & 4 & 10 & 45 & 3.4 \\
\hline Multi-C & 1 & 2 & 1 & 0 & 3 & 1 & 2 & 2 & 1 & 5 & 0 & 19 & 1.4 \\
\hline S-P & 19 & 4 & 1 & 0 & 1 & 7 & 0 & 10 & 2 & 13 & 1 & 58 & 4.4 \\
\hline P-C-P & 2 & 0 & 0 & 0 & 3 & 2 & 2 & 0 & 4 & 0 & 1 & 13 & 1 \\
\hline Total & 121 & 91 & 60 & 52 & 72 & 156 & 103 & 160 & 151 & 181 & 117 & 1330 & \\
\hline
\end{tabular}
(4e).

Table 5. Syntactic Variants of the Simple Sentence and their Distribution 
(4a)||This |is |Nigeria.||(AA Q1 R)

(4b)||The educational system |is |bankrupt.||(UDP Q6 R)|

(4c) || $\mathrm{We} \mid$ have| enormous oil and gas resources.||(ADC Q1 R)

(4d)||We |can build |small-scale refineries.||(UDP Q3 S)

(4e)||Our situation |requires |such emergency measures.||(UPP Q6 S)

The following sentences exemplify the || $\mathrm{S}|\mathrm{P}| \mathrm{A} \|$ structural pattern.

(5a)||The factories |have been turned |to churches.||(ACPN Q2 R)

(5b)||They |are diverted |for private consumption.||(KOWA Q4 R)

(5c) ||We| cannot develop| that way.||(NCP Q4 C)

(5d)||Something has to be done labout our grazing system.||(UDP Q7 S)

(5e)||That cartel | must be removed | completely.||(UPP Q3 S)

Lastly, sentences manifesting the full $\|\mathrm{S}|\mathrm{P}| \mathrm{C} \mid \mathrm{A}\|$ realisation of clause structure are illustrated as in (6a)-(6f). Notice repetition in (6a).

(6a)||We| will place |emphasis |on solar.|| ||We |will place |emphasis |on coal.|| ||We |will place| emphasis |on even the wind power generation.||(HDP Q2 C)

(6b)||There |will be| no hiding place |for corrupt people.||(UPP Q4 C)

(6c)||We |have brought |railway| back.||(PDP Q8 S)

(6d ||But| there |is |too much government involvement| in educational institutions. | (UPP Q6 C)

(6e) $\mid$ We | must have | the right values $\mid$ as a people.||(NCP Q5 S)

(6f) ||We| must arrest| this slide| downwards.||(KOWA Q8 S)

The foregoing paints a picture of syntactic simplicity because the nominal groups (NMGs), verbal groups (VBGs), adjectival groups (AJGs), adverbial groups (ADGs), and prepositional groups (PRGs) realising elements of clause structure are structurally H-Type and MH-Type. But this is only superficial: Most elements of clause structure were indeed realised by structurally HQ-Type and MHQ-Type groups, with some manifesting subordination at Q. The need to pack in as much information as possible into a single element of structure, which is symptomatic of semantic complexity, explains this phenomenon. Thus two sets of the kernel sentence, corresponding roughly to van Leeuwen's (2012) absence or presence of complementation constructions effects, are identifiable. Each element of structure of the second set is therefore examined more closely.

(a)The Subject

Some form of syntactic complexity was introduced into the kernel sentence when the NMG in subject position had a rankshifted clause or PRG as Q. In (7a)-(7f) rankshifted clauses as Q are illustrated. They provide further information on the noun headwords and help to distinguish them from similar ones.

(7a)||The federal government [[led by the NCP]]| will not farm.||(NCP Q7 S)

(7b) ||One thing [[that is associated with the upstream that he did not mention]] | is| the issue of stealing.|| (PDP Q3 R)
(7c)||The police force [[we have today $]] \mid$ have been reduced |to their shadows.||(HDP Q5 R)

(7d)||The system [[we inherited]] |is | defective.||(UDP Q4 R)

(7e) ||Our former heroes [[who fought for our independence $]] \mid$ set| us |on the right track.|| (KOWA Q1 R)

(7f)||Those [[who are teaching in educational schools $]]$ must be trained| [[to really teach]].|(UPP Q6 S)

The following sentences show subjects realised by NMGs with rankshifted PRGs as Q, which serve to properly define or situate the headword.

(8a)||The youths [of this country] |are| ready.||(AA Q2 S)

(8b) ||All [of us] |promise |the same things||(NCP Q1 S)

(8c)||The days [of groundnut pyramid] |are| over||(PDP Q7 S)

(8d)||The people [in that region] |are drinking |benzene| in their water.|(APA Q3 R)

(8e) ||A lot $[$ of jobs]| will be created |in the railway sector.|(ACPN Q1 S)

While (8a)-(8e) may be somewhat innocuous (9a)-(9c) are not because the Qs also have rankshifted clauses as their own Qs (marked bold), introducing further syntactic complexity into an otherwise structurally simple sentence. These secondary qualifiers provide additional detail and make more explicit the headwords' referents.

(9a)||The whole [of Adamawa State] [[that seven local government areas were under the terrorists]] | have been taken over.||(PDP Q5 S)

(9b) ||The two local governments [in Yobe State [[that were under terrorists]]| have been taken over.|| (PDP Q5 S)

(9c)||And |most $\mid$ of the territories [[occupied by the insurgents]] |are |now |recovered.|| ||Still,| the girls |are missing.||(UPP Q5 R)

(b)The Predicator

Though complex catenated VBGs functioned as predicators, none featured more than one layer of group subordination. There however occurred particles in secondary qualifier function as in (10e)-(10f) below. A catenated VBG indicates at least two actions, events, processes etc depending on its complexity. For instance, the H-element of (10a) expresses AD's future intention to undertake a process conveyed by the to-non-finite form at Q meaning purpose (Notice that in (9a)-(9b) above the predicators are structurally compound, particled MHQ-Type VBGs)).

(10a)||We| want to diversify |on the sources of electricity.||(AD Q2 S)

(10b)||I |love to give | permanent, technical solutions | to artificial problems of corruption.|| (AA Q4 S)

(10c)||I |'d like to tackle | this issue of corruption |on two levels. |(KOWA Q4 S)

(10d)||KOWA Party |will seek to address |these two dimensions.||(KOWA Q6 S)

(10e) $\|$ We | intend to cut down lon the excesses of government.|(ADC Q1 S)

(10f) || $\mathrm{We} \mid$ need to go back |to [[developing our export crops]].||(KOWA Q7 S)

(c)The Complement

Complements also featured NMGs with rankshifted clauses or PRGs at Q as (11a)-(11b) and (11c)-(11d) respectively illustrate, with the same effects as those of subjects. 
(11a)||Then| we |must do | things [[that will bring about development]].|(UDP Q1 S)

(11b)||These |are |the things [[we need to tackle]].||(HDP Q4 C)

(11c)||I |thank| all [of you] |for listening.||(UDP Q8 C)

(11d)||These | are | the drawbacks [.of the old system of farming]].|(UDP Q7 R)

Notice that the Q-element in (11e) below is indeed the remnant of a rankshifted clause reconstructed as (11f).

$$
\mathrm{S} \quad \mathrm{P} \quad \mathrm{C}
$$

(11e)||Nobody |promises |anything different.||(NCP Q1 S)

$$
\mathrm{S} \quad \mathrm{P} \quad \mathrm{C}
$$

(11f)||Nobody |promises |anything [[that is different $]]$.||

It has so far been shown that the subject and complement can be realised by NMGs with the rankshifted clause at Q, but the data also provides evidence of NMGs at both $\mathrm{S}$ and $\mathrm{C}$ exhibiting rankshifted clauses at $\mathrm{Q}$. This is proof that the structurally simple sentence can otherwise be 'complex' in its own right.

(11g)||Everybody [[that has to be appointed to serve under my cabinet $]$ |will follow |the same method [[that I will follow]].|| || And |that| is| [[making your assets public]].|(CPP Q4 S)

Evidence of structurally disrupted HQ-Type NMGs at C, occasioned by the need to bring the adjuncts into semantic prominence through syntactic prominence, is provided by (12a).

$$
\mathrm{S} \quad \mathrm{P} \quad \mathrm{C}-\mathrm{A} 1 \quad \text { A2 } \quad-\mathrm{C}
$$

(12a) ||We | have| agencies | presently |in this country|[[that are supposed to be in charge of corrupt practices]]\| (APA Q4 R)

The significance of A1 and A2, which respectively express time (presently) and location (in this country), would have been lost had they been postponed to the usual end position. So, their inversion is for greater effect as the speaker stresses the time as now, not past or future, and the location as Nigeria, not elsewhere, and appears to be saying matter-of-factly thus: I am addressing the issues that concern us as a nation at the moment.

Some NMGs at $\mathrm{S}$ or $\mathrm{C}$ with the rankshifted clause or PRG at $\mathrm{Q}$ are analysed in (12b) and (12c) respectively.

(12b) M

$$
\begin{array}{lll}
\mid \text { the } & \text { things } & [\text { we need to tackle }]] \mid \\
\mid \text { The federal } & \text { government } & \text { led by NCP }]] \\
& \mid \text { thing } & {[\text { [that will bring about }} \\
& & \text { development }] \mid
\end{array}
$$

One thing [[that is associated with the upstream that he did not mention]]

|The police force [[we have today]]|

|Our former heroes [[who fought for our independence]]|

|The $\quad$ system [[we inherited]] |anything [[that is different]]|

|Those [[who are teaching in

$\begin{array}{ccc} & & \text { educational schools }]] \\ \text { (12c) } \mathrm{M} & \mathrm{H} & \mathrm{Q} \\ \mid \text { The } & \text { youths } & \text { [of this country }] \\ \mid \text { The } & \text { days } & \text { [of ground pyramid] } \mid \\ \mid \text { the } & \text { drawbacks } & \text { [offarming, oftheoldsystem of } \\ & & \text { farming] }\end{array}$

$\begin{array}{llc} & \mid \text { All } & {[\text { of us }] \mid} \\ \mid \text { The } & \text { people } & {[\text { in that region }] \mid} \\ & \mid \text { all } & {[\text { of you }] \mid} \\ \mid \text { A } & \text { lot } & {[\text { of jobs }] \mid}\end{array}$

The only structurally complex AJG in complement function is analysed linearly and diagrammatically in (12d)(12e) and can be viewed in its clause context in (14d) below. (2d) $\mathrm{H}$

|cheaper|than the chicken [[that is produced locally]] |(KOWA Q7 R)

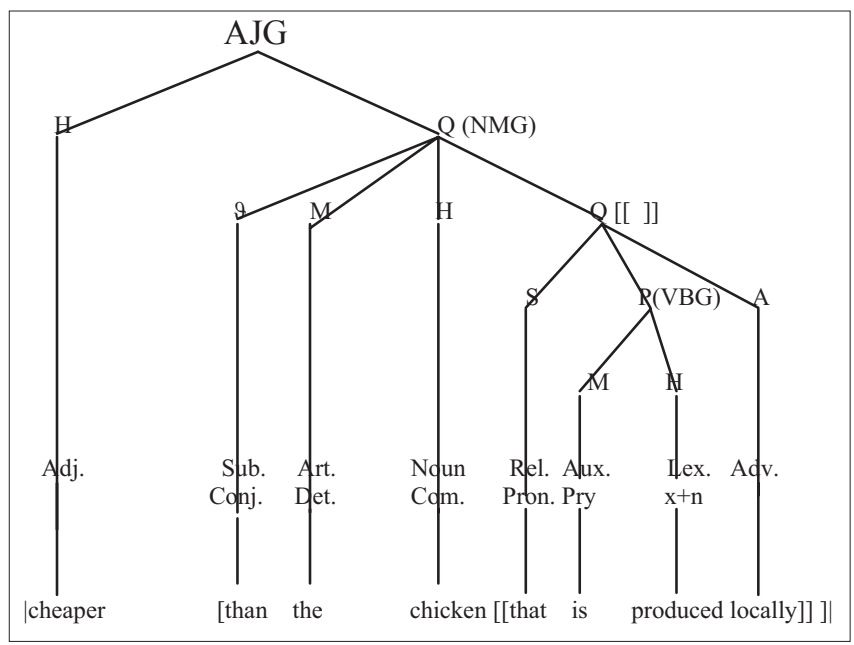

(d) The Adjunct

Complexity was introduced into the adjunct position when the PRG had another PRQ subordinated to it. Here are examples.

(13a)||Great strides| are being made| in the realm [of agriculture] $\|($ KOWA Q7S)

(13b)||There |is |deprivation |in the midst [of plenty].||(ACPN Q3 R)

(13c)||There | are | two issues | to the problem [of corruption in Nigeria]. |(ADC Q4 R)

Not only were there two layers of group subordination there also were clausal subordination and nominalised clause as PRG qualifier as in (13d), (13e), and (13f)-(13g), respectively.

(13d)||KOWA Party | identified| education | as one [of the evils [[bedevilling our society]]].|| (KOWA Q6 R)

(13e)||There | are | over 5000 appeal cases [[waiting for judgement]].|(APA Q4 R)

(13f)||The problem of injustice.| is| very cardinal| to [[finding solution to the problem of insecurity $]]$.|(APA Q5 S)

$(13 \mathrm{~g})|| \mathrm{We} \mid$ can stop $\mid$ that $\mid$ by $[[$ strengthening the judicial system]].\|

(ADC Q4 S)

Finally, an instance of rankshifting at Q in both subject and adjunct positions is:

(13h) ||The road map [[we have ]] is |for an integrated power system [[that will certainly give us the kind of energy we need to power our engine of growth]].|(ADC Q2 C)

The PRG diagrammed below in order for its complexity to be fully appreciated has eight layers of group and clausal subordination. 


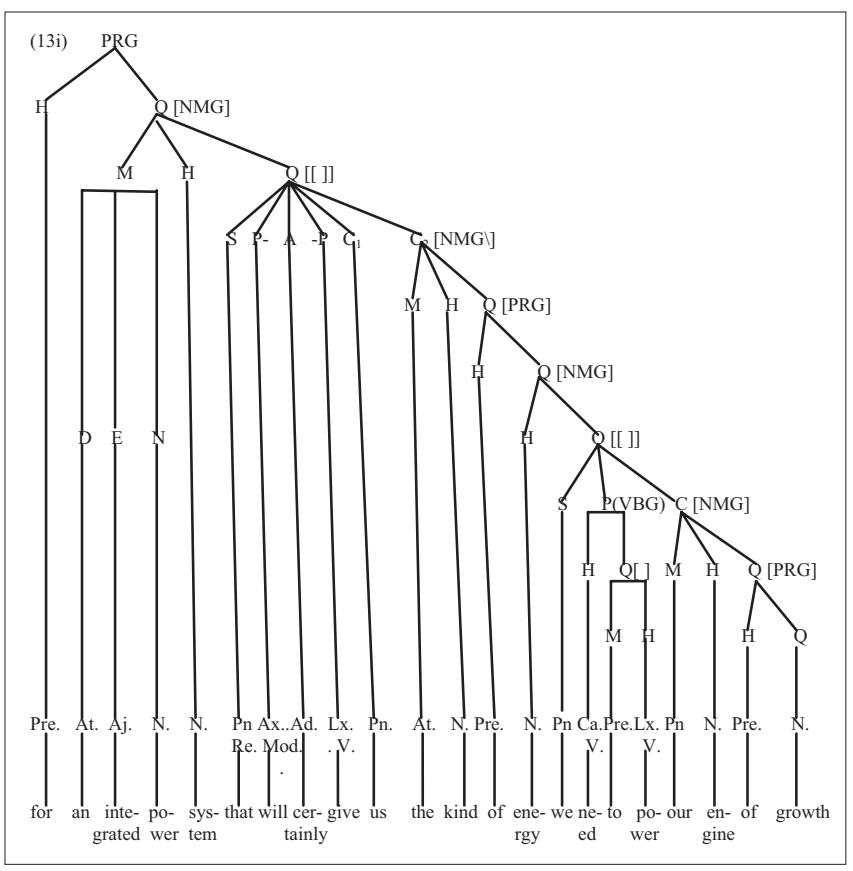

\section{The rankshifted clause as an element of clause structure}

Simple sentences manifesting rankshifted clauses as elements of clause structure represent a significant 21 per cent (281). Their presence is indicative of syntactic complexity and grammatical sophistication, the absence of subject-complement-adjunct and subject-adjunct subtypes notwithstanding. Rankshifted clauses generally made more explicit debaters' intentions because of their capacity to contain large amount of information that would have probably taken several simple sentences to convey. Each variant is examined closely as follows.

(a)The Rankshifted Clause as Subject ([[S]])

Thirteen simple sentences had nominalised clauses as subject and only one was non-finite. The finite clauses were initiated by what mainly, as only one instance each of that and how occurred. The examples that follow reflect these facts accordingly.

(14a) |[[ Flaring gas up to this point of our national development]]| is |also |another embarrassment| [[because there are so many uses to which the gas can be put]].\|

(UPP Q3 S)

(14b) ||[ $[$ What we are bringing to the table $]]$ is | the decentralisation of power in Nigeria.|| (ADC Q2 S)

(14c) $\|[[$ That we have less than 300,000 policemen $]]$ | is $\mid$ crass irresponsibility.|(UDP Q5 R)

(14d) $\mid[[$ How come imported chicken $]] \mid$ is $\mid$ for instance,| cheaper [than the chicken [[that is produced locally]]]?|(KOWA Q7 R)

(b)The Rankshifted Clause as Complement ([[C]])

Simple sentences with the rankshifted clause as complement were the most numerous and they were formally far more finite than non-finite. The finite clauses were mostly that-clauses, collocating with verbs like believe, hope, ensure, realise, and convince which stress debaters' conviction about the veracity of the statements made.

(15a) || We |believe|[[that we can create economy big enough to provide jobs for all]]. || (AD Q1 S) (15b) $\|$ We | will ensure $\mid[[$ that each state of the federation. establishes its own power plant]].|(ACPN Q2 S)

(15c) ||But | it| is| sad|[[that Nigerians can't even go to. good school without paying with an arm and a leg]].\|

(UDP Q6 R)

(15d) $\mid$ We $\mid$ realise |[[that the policy of energy conservation has not been introduced in this country]].\|

(CPP Q2 R)

Some that-clauses really got complex with internal subordination but with great expressive efficiency as compensation. Consider this:

(15e) ||In the downstream sector we will not privatise |..|We |will make |sure | [[that the refineries which had been owned by us for decades and which have run successfully in the past will run successfully again]].\|

(NCP Q3 S)

There occurred syntactically understood that-clauses without the relative pronoun present.

(16a) || $\mathrm{I} \mid$ believe $\mid[[$ it is important for us to retrace our steps]].|| ||That's [[why I'm here]].\|

(KOWA Q1 C)

(16b)|| It | shows |[[our education is defective ]].|(UDP Q8 R) In addition, there featured other clauses indicating position, reason, and time thus:

(17a)||This |is |[[where the challenge really lies also apart from security for Nigeria at this time]].\|

(KOWA Q3 R)

(17b) ||That |'s| [[why we are looking at agric as a business, not just a rural programme]].|(PDP Q7 S)

$(17 \mathrm{c})|| \mathrm{This} \mid$ is | [[because we are paradoxically importing. what we produce]].|(NCP Q3 R)

(17d) ||We |must realise |[[that the ultimate success in the renewed onslaught against the insurgents should be the bringing home back safely of these Chibok girls]]. . ||That | is| [[when our celebration can really be full and meaningful]].|(KOWA Q5 R)

A context where clauses initiated by interrogative adverbs and interrogative pronouns occurred in a sequence for maximum effect is

(17f)(How did our friends, the Asians, develop.? They didn't tolerate corruption.) ||So| I| do not see|[[how a government. will play down such important issue]].|| || That |'s | [[where leadership counts]].|| ||That| 's|[[ what I want to offer]].|(HDP Q4 R)

Non-finite clauses as complements featured all four forms but only one each of $x+o$ and $x+n$.

(18a) ||So |the first thing [[you have to do to reduce this insurgency.]] |is |[[engage the youth]]. || (APA Q5 S)

(18b)||But| Nigeria| is not| [[that structured]]|[[to benefit all that from agriculture]].|(UPP Q7 R)

(18c) ||The case of prevention | is |[[ making sure that nobody even has the opportunity to steal what belongs to the public]].|(PDP Q4 S)

(18e) || Our simple strategy $\mid$ is $\mid[[$ to review. the national agriculture system]].|(NCP Q7 S)

(18f) $\|$ Our commitment $\mid$ is |[[to make sure that it is opened up to private sector investment]]. (PDP Q3 S)

(c)The Rankshifted Clause as Adjunct ([[A]])

Again, both finite and non-finite clauses were rankshift- 
ed to function as adjuncts. The finite clauses featured overt markers of subordination and these were quite diverse formally and semantically, expressing time, place, and condition as (19a)-(19b), (19c), and (19d)-(19e) respectively show.

(19a)||So |export| will be| the major area of our economy |[[when we come in $]] . \mid(\mathrm{AD}$ Q1 C)

(19b)||There |are| people who are admitted to teach|[[ when they are not equipped to teach]].|(UPP Q6 R)

(19c)||You | must have| teacher training colleges |[[ where teachers are taught how to be teachers]].|(UDP Q6 S)

(19d)||Nothing| moves |[[unless you have education]].||(UDP Q5 S)

(19e)||So | they | are administrative and bureaucratic challenges that will reduce cost |[[if they are properly managed]].||(NCP Q3 R)

They also indicated reason as the following because- and so that-clauses illustrate.

(19f)||KOWA Party |will pursue |sufficiency | in grain production|[[because this is important $]] . \mid($ KOWA Q7 S)

$(19 \mathrm{~g})|| \mathrm{We} \mid$ are | no longer | talking about | groundnut pyramid |[[because we are not going to export raw materi$a l]] . \|((P D P$ Q7 S)

(19h)||Our religious leaders | have to do | a lot $\mid$ in this aspect|[[because some of these things are sparked off from the religious point of view]].|(CPP Q5 S)

(19i)||We, our government | shall go for | resource control |[[so that those who have whatever God has given them will.produce and contribute to the centre]].|(UPP Q7 S)

(19j)||They |have to reach |the international standards |[[so that our communities will not be hostile]].|| (CPP Q3 S)

Below is one simple sentence characterised by grave internal syntactic complexity. Its adjunct, a twenty-nine- word long complex sentence in its own right, is split in two halves by a syntactically unconnected but textually related clause (bracketed) that affirms the factuality of A's content. Its effect would have been lost had it been delayed till the end. This shows how a debater's desire to achieve a mediate goal impacts syntactic structure.
S P
$\mathrm{C}_{1}$
$\mathrm{C}_{2}$
A-

(19k) || I| am |happy |[[you asked this question]]|[[because, if we do not deal with corruption, and corruption continues to erode developmental funds, especially for

election purposes]].|(||The data |is |clear||)[[then, we will not have funds to fund developmental projects]].||(NCP Q4 R)

Rankshifted non-finite clauses in adjunct position were majorly $t o+x+o$ expressing purpose and result as in (20a)(20d) and (20e)-(20h) respectively.

(20a)||God |will not come down| from heaven |[[to create jobs for Nigerians]].|(ACPN Q1 R)

(20b)||It |'s | time | [[to work]].|| ||Nigerians,| let |'s| set out | [[to work $]] . \|($ KOWA Q8 C)

(20c)||And | we | ask |you | [[to join us, the PDP government]] | for the next four years.||(PDP Q8 C)

(20d)|| It| matters |a lot |[[to prosecute offenders]].||(CPP Q5 R)

(20e) || $\mathrm{We} \mid$ have to process $\mid$ the groundnut |[[ to add value to it.]].|(PDP Q7 S)
(20f)||The advanced technology |will make |it| impossible| [[to engage in corruption $]]$.|(AD Q4 S)

$(20 \mathrm{~g})||$ You |don't need to be |corrupt |[[for you to get anything]].|(AA Q4 R)

(20h) $\mid$ We |are structured $\mid[[$ not to even become ingenious ]].|(UPP Q7 C)

The only instance of $\mathrm{x}+\mathrm{n}$ usage is (20i); none of $\mathrm{x}+\mathrm{g}$ or $\mathrm{x}+\mathrm{O}$ was found.

(20i) ||We| have |enough power |[[to go round]]|[[based on what we are producing. $\|(\mathrm{CPP} \mathrm{Q} 2 \mathrm{~S})$

(d)The Rankshifted Clause as Subject and Complement $([[\mathrm{S} \& \mathrm{C}]])$

Three syntactic patterns were associated with simple sentences manifesting rankshifted clauses in both subject and complement positions. First, both clauses were formally finite. Second, the one was finite and the other non-finite. Third, the complement was multiple and morphologically $x+o$ as (21a) (21b), (21c)-(21d), and (21e)-(21f) respectively illustrate.

(21a)||[[Why I want to be president of Nigeria $]]$ is [[because I know that there are problems to be solved in this country]](CPP Q1 R)

(21b)||What I would also like to suggest for the whole of the north-eastern part of our country.]]| is| [[that we set in place something like the marshal plan.]].||(KOWA Q5 S)

(21c) ||$[[$ What we need to do in this country] $]$ is|[[ to create jobs for the people]]||(ACPN Q3 S)

(21d) $\|[[$ What we need now $]]$ |is |[[to create a new Nigeria through new leadership that will secure the future of our children]].|(HDP Q1 S)

(21e) ||$[[$ What Nigerians need to do] $] \mid$ is $\mid[[$ look among the contestants]] |and | [[see who among them exemplify a good leader ]]. |(HDP Q1 S)

(21f) $\mid[[$ What we are going to simply do $]]$ is |[[take each federal education institution]],| [[do a gap analysis, world class standards versus where we are]]|, |[[we come up with a gap closure plan]].|(NCP Q7 S)

(e)The Rankshifted Clause as Complement and Adjunct $([[\mathrm{C} \& \mathrm{~A}]])$

Where the complement and adjunct were realised by rankshifted clauses, the clauses were either finite or mixed as shown below.

(22a)|| I |want to say | [[thank you]]| [[because it is our collective resilience that has kept this nation from tottering into that precipice.]].|(KOWA Q1 R)

(22b) ||We |will ensure |[[that there is education $]]||[[$ so that $\mathrm{Ni}$ gerians will know we are way out of line]].|(HDP Q4 S)

(22c) || I | believe |[[ that we have what it takes to reconstruct this apparatus we inherited from the British]]| to produce the development that will make Nigerians happy.]].| (UDP Q1 C)

(22d)||And| that |is |[[why we are here to present ourselves and our programmes]]| [[to ensure that Nigerians begin to have a choice of leadership]].||(HDP Q1 R)

\section{Multiplicity of the complement and adjunct}

Five per cent (64) of the simple sentences was affected by multiplicity of elements of structure which involves the 
complement and adjunct only and which was exploited by debaters to provide additional detail and elucidate points. Each element of structure is considered separately.

(a)Multiplicity of the Complement (Multi-C)

Multiple complements were realised either by NMGs only (e.g.,..... (23a)-(23b)), NMGs and finite clauses (e.g.,.,., (23c)-(23d)), AJGs and finite clauses (e.g.,...,. (23e)), interrogative clauses (e.g.,.,.,. (23f)), or $x+o$ non-finite clauses (e.g.,.,.., (23g)). While the initial complement specified the beneficiary of the verbal action the second identified the entity concerned. Notice appositive structures specifying the change desired in (23e) and enumeration in $(23 \mathrm{~g})$.

(23a) ||We |will give| them |support |[[so that not only.]].|(ACPN Q3 S)

(23b)||Those that benefitted from this system | have made |it | a business enterprise.||(UDP Q6 R)

(23c)||We |will offer |Nigerians |[[what we think is lacking]]. |(HDP Q1 S)

(23d)||Thank $\mid$ God $\mid[[$ they are gradually coming back]].||(KOWA Q7 C)

(23e)|| But |I |'m | sure| [[everybody wants change, change that will torch lives, change that will make every Nigerian comfortable]].|(UPP Q1 R)

(23f)||But |the key issue | is |[[how do we prevent such $]]$ and |[[how do we provide security for all Nigerians?]].||(PDP.Q5 S)

(23g)||Our strategy to deal with downstream sector |is |(1) [[restore existing domestic capacity]]| (2)[[upgrade existing refineries]].|(NCP Q3 S)

(a)Multiplicity of the Adjunct (Multi-A)

Clauses with two adjuncts were the most numerous. As (24a)(24e) show, no two ADGs co-functioned but there were two PRGs and two non-finite clauses. Moreover, each adjunct indicated a different relationship with the predicator and this greatly enhanced speakers' capacity to achieve set goals.

(24a)||A UPP government | believes | very strongly | in state policing.||(UPP Q5 S)

(24b)||The amount of money [[put in the 2015 elections]] can transform |Nigeria $\mid$ from a third world country| to a first world country \|\| $\mathrm{We} \mid$ cannot continue |like this $\mid$ as a people.|| (NCP Q4 C)

(24c)||An individual| cannot fight| corruption |in this country |[[except we all come together]].|(ACPN,Q4 C)

(24d)||All |will be overseen| by government |[[to ensure that they meet the standards]]. || (NCP Q6 S)

(24e)||And| we |must have | the political will |[[ to be able to prosecute offenders]]|[[to teach a lesson to others]].||(CPP Q3 S)

Syntactic complexity and semantic complexity heightened with increased number of adjuncts. The only three-adjunct clause has its first adjunct placed before the complement, which means the speaker holds the means rather than the end in greater reckoning.

$$
\begin{array}{llll}
\mathrm{S} & \mathrm{P} & \mathrm{A}_{1} & \mathrm{C}
\end{array}
$$

(24f) || $\mathrm{We} \mid$ will encourage $\mid$ through regulation $\mid$ the states $\mathrm{A}_{2}$ $\mathrm{A}_{3}$

$\mid[[$ to take charge of some of these areas $]] \mid[[$ to ensure that they themselves are in control]].|(HDP Q2 S)
Remarkably the four- and five-adjunct clauses came from the same source. Sentence $(24 \mathrm{~g})$ is a non-polar interrogative clause with four adjuncts realised by a PRG and three syntactically identical rankshifted finite clauses that are in semantic opposition temporally with the PRG. The choice of mood and adjuncts is both thematically and grammatically relevant (cf.(36b) below)).

(24g)||Why |do |we |have to wait| to this point |[[before we begin to motivate]],|[[before we begin to equip]],|[[before we begin to do things we ought to have done a long ago]]?|(UPP Q5 S)

In $(24 \mathrm{~h})$ below, the first adjunct, a PRG, is fronted to quickly place the action conveyed by the VBG of negative polarity at $\mathrm{P}$ in spatial perspective while the rest, all to-nonfinite, express the specific actions denied.

(24h) || $\mathrm{We} \mid$ are not designed $\mid$ in Nigeria $\mid[[$ to challenge leaders, $]] \mid[[$ to be creative, $]] \mid$ [[to be able to explore and exploit the comparative advantage that they have from their various zones]].|(UPP Q1 R)

Ignore the inappropriateness of the initial preposition by and of tense, and it will be hard not to appreciate how the five adjuncts in (24i) contributed in identifying the rot in the educational sector.

\section{$\mathrm{A}_{1}$}

(24i)||By the time we begin to admit people into universities by quota system,

$$
\mathrm{A}_{2} \quad \mathrm{~A}_{3}
$$

by educationally disadvantaged, $\mid$ in such a way that somebody who had scored highly is

now denied admission in favour of somebody who scored very poorly,

$\mathrm{A}_{4}$

$\mathrm{A}_{5}$

on account of where he comes from,| in order to make that area catch up with the others,

$\mathrm{S} \mathrm{P} \quad \mathrm{C}$

that $\mid$ was $\mid[[$ when educational standard began to drop]].||(UPP Q 6R)

The last sentence exemplified here has two complements that assert the speaker's candidature and two adjuncts that identify the position sought $\left(\mathrm{A}_{1}\right)$ and why $\left(\mathrm{A}_{2}\right)$. Of interest are the layers of group subordination in the $\mathrm{PRG}$ at $\mathrm{A}_{\mathrm{I}}$.

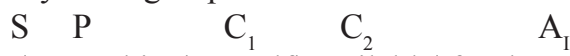

(24k)||I |am making| myself| available| for the position of the President of the Federal

$\mathrm{A}_{2}$

Republic of Nigeria | [[because I want things to change]].|(UPP Q1 R)

\section{Mobility of the adjunct}

Adjuncts ordinarily occupy the last slot and are the only syntactically mobile element of clause structure. Because they generally make reference to the circumstances of the verbal situation and comment on the propositional content of the clause (Quirk et al, 1985:730), moving adjuncts to other positions suggests the speaker intends to purposely highlight the specific meaning indicated for greater effect as this data shows. This is in agreement with Millar and Curie's (1972) report that adjuncts transferred from sentence end execute 
both thematic and structural functions. Mobility affected 10 per cent (131) of simple sentences with eighty-two adjuncts occurring clause-initially, thirty-two at median position, fifteen after the subject, and two before the complement. These positions are examined separately.

(a)Initial Adjunct (Initial A)

In addition to the intrinsic meanings that ADGs, PRGs, NMGs or rankshifted clauses in adjunct function indicated, adjuncts at clause initial were fore-grounded for emphasis or specificity. In (25a)-(25b), for instance, the speakers lament the economic and security situations in Nigeria as part of their recognition of the problem.

(25a)||Unfortunately for the past fifty years |we |have been going about| with an economy of twenty million | in. a nation of over hundred million.||(AD Q1 R)

(25b)||But| unfortunately for Nigeria within this period | we| have |this terror attacks |from the North.|| (PDP Q5 R)

Fronting adjuncts aided listeners' capacity to quickly identify speakers' focus on specific issues as if contrasting these with what had been.

(25c)||In the petroleum sector | what bothers Nigerians and which government must really strengthen and properly look into in the next four years $\mid$ is $\mid$ the issue bordering on proper management.||(PDP Q3 R)

(25d)||Thirty years ago | the railway system| collapsed |completely.|(PDP QI R)

(25e)\|Recently | Bishop Matthew Kukah |identified same, that leadership is our problem.||(HDP Q1 R)

(25f)||Before this time| guinea worm |was a problem.|| ||Now |we have | eradicated that in some parts of this country. |(PDP Q1 R)

(25g)||In the first republic | regions | were contributing | to the centre.|(UPP Q7 R)

(25h)\|From our perspective |the problem with Nigeria |is |leadership.||(NCP Q1 R)

It becomes easy to appreciate how initial adjunct convergence impact meaning and textuality as in (25i), where NCP demonstrates that security agencies' negative attitude gravely compromises security in Nigeria.

(25i) ||Just a few weeks back |we |know |about the robbery | in Lekki Phase 1 | in Lagos.|| || It| lasted |over an hour.|| ||At the gate of the estate |there $\mid$ is $\mid$ an armoured personnel carrier.|| ||It |did not respond.|| ||By the foot of the bridge,| two blocks away| there| is |an RSS Station.|| It is not just about money, money, money. We must have the right values as a people.(NCP Q5 R)

Adjuncts at sentence initial also indicated where, how and why the specified actions would be taken.

(25i)||In every state of the federation | the federal government | should be able to have |teacher training colleges.||(UDP Q6 S)

(25j)||In terms of the import bills, | you | know | [[that we dropped by almost two-thirds.]].|(PDP Q7 S)

(25k)||By virtue of the advancement of society $\mid$ there |is |definitely $\mid$ need $\mid$ [ [ to be changes in the way things are done]].|(UDP Q7 R)'

(251)||Normally $\mid$ there $\mid$ will be $\mid$ palliatives that will be made available to them. $\|($ UDP Q5 S)
Adjuncts at clause initial also occurred in multiples. While $(25 \mathrm{~m})$ may be considered superfluous, thematic foregrounding of adjuncts in (25n) effectively surmises the pervasiveness of insecurity in Nigeria.

(25m)||In addition to that $\mid$ in this country | a few decades back,| before our democracy in quote,| we |had |agric extension services| in this country.||(NCP Q7 S)

(25n)||With the level of unemployment, | with the level of corruption,| with the level of impunity, very vexatious impunity that the political rulers of Nigeria exhibit, | it provokes people to follow their.line of lawlessness, their line of crime.||(NCP Q5 R)

(b) Adjunct after Subject (A after S)

Adjuncts occurring after the subject but before the predicator were syntactically H-Type ADGs and semantically additives and amplifiers, with also featuring most prominently.

(26a) || $\mathrm{I} \mid$ also | congratulate | my co-contestants |[[for coming to the board]]. |(APA Q1 R)

(26b) || I |strongly |believe |[[if we fix the educational system in Nigeria every other problem will follow suit]].||(ADC Q1 S 2)

(c) Adjunct before Complement (A before C)

Positioning the adjunct between the predicator and complement served to amplify the complements themselves, as (27a)-(27c) illustrate.

(27a)||There |is| absolutely | no justification|[[for us to be where we are]].|(NCP Q1 R)

(27b) ||So |we |'ve said | majorly |[[crimes are of course fuelled by unemployment]].||. ||It |is |usually $\mid$ vindicating. ||(HDP Q3 S)

(27c)||The attraction of public office in terms of remuneration $\mid$ is $|j u s t|$ too great.||(KOWA Q4 R)

(d) Median Adjunct (Median A)

Adjuncts splitting structurally compound or complex VBGs at $\mathrm{P}$ were realised mainly by $\mathrm{H}$-Type ADGs, occurring in multiples and even disrupting rankshifted clauses at $\mathrm{C}$ as (28a)-(28c) respectively illustrate.

$$
\begin{array}{llllll}
\mathrm{S} & \mathrm{P}- & \mathrm{A}_{1} & -\mathrm{P} & \mathrm{C} & \mathrm{A}_{2}
\end{array}
$$

(28a) ||We |will| also | want to look at |wind |as well as tidal energy.\|

$\mathrm{S} P-\mathrm{A}_{1} \quad-\mathrm{P} \quad \mathrm{C} \quad \mathrm{A}_{2}$ |We |will| certainly |go into| nuclear |for peaceful means $+\quad \mathrm{A} 3$

|and| for production of power.||(ADC Q2 S)

$$
+\begin{array}{lllll}
\mathrm{S} & \mathrm{P}- & \mathrm{A}_{1}-\mathrm{P} & \mathrm{A}_{2} & \mathrm{C}
\end{array}
$$

(28b) || But $|\mathrm{I}|$ have to $\mid$ really $\mid$ say $\mid$ as a democratic person $\mid[[$ that our law regarding terrorism is $\mid$ still |somehow| backward]].|(CPP.Q5 R)
$\mathrm{A}_{1}$
$\mathrm{S} \quad \mathrm{P} \quad \mathrm{C}_{1}$
$\mathrm{C}_{2}$

(28c)||In addition to that,| we| will make |sure |[[that corrup $\mathrm{A}_{2}$

tion is completely controlled]]| [[because corruption is at the root of mal-governance in Nigeria]].|(NCP Q8 S)

Lastly, while (28d) instantiates MH-Type ADG, (28e) illustrates a context in which splitting adjuncts of different semantic categories enhanced textual cohesion and aided the articulation of the debater's goals through restatements. 
(28d)||We |will| no more |have| this experience of unemployment $\|(A D$ Q1 S)

(28e) ||But |most of that fund |was |isolated |from government $\|$. || Government |is not $\mid$ directly $\mid$ involved. \|\| In fact,| now |we |have |even |introduced| drones.|| ||We |'ve | never| had |it |before.|| ||We |are |also |using| drones |for remote sensing. |(PDP Q5 S)

\section{Inverted sentences}

Seventy-two (5.4 per cent) cases of clausal inversion were identified and they were 97 per cent grammatically necessitated, involving subject-predicator inversion and predicator-complement-predicator inversion.

(a)Subject-Predicator Inversion(S-P)

Subject-predicator inversion associated with clauses marked for interrogative mood was the dominant form of inversion seen and this was both polar and non-polar.

(29a) || $\mathrm{We} \mid$ believe $\mid[[$ that we can create an economy big enough to provide jobs for all.

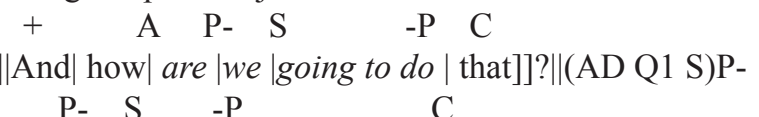

(29b) ||Must $\mid$ we $\mid$ build $\mid$ a humongous refinery [[that will take all the money in our economy to build and maintain]]?|(UDP Q3 S)

$$
\mathrm{A}_{1} \mathrm{P}-\mathrm{S} \quad \mathrm{P} \quad \mathrm{C} \quad \mathrm{A}_{2}
$$

(29c)||How|do|we |run |sewage |without water?||

$$
\text { A1 C P- S -P A2 }
$$

||How $\mid$ much $\mid$ does $\mid$ it $\mid$ cost $\mid[$ [ to build $\mid$ an industrial borehole]]? ||(NCP Q5 R)

In (29d), the subject, predicator and complement are in reversed order. The speaker's answer to his own question using a minor sentence is his selling point in the contest, and this is reiterated in the declarative clause where an identical non-polar interrogative clause serves as complement.

$$
\begin{array}{lllll}
\mathrm{C} & \mathrm{P} & \mathrm{S} & \mathrm{C}_{1} & +
\end{array}
$$

(29d)||What |is |the difference?|| ||The integrity of the party |and

$$
\begin{aligned}
& \mathrm{C}_{2} \\
& \text { |the integrity of the candidate.|| } \\
& \mathrm{P}
\end{aligned}
$$

$\mathrm{S} P$

||That| is| [[what makes the difference]].|(NCP Q1 C)

It happened that one debater might have found questioning as effective technique for recognising the problem and specifying actions to be taken thus (cf. (32a) below)):

(29e)Thank you very much. Why are we where we are today? And will anybody tell us. that in Nigeria we don't have resources to provide solution to this problem of power? We have resources. Where are we today? Our hydro-dam have (sic) about sixteen blades. As of today, how many blades are working there? Maybe four. What's the problem? What's wrong with the other twelve? Why are they not working? I mean what is stopping them from working? (AA Q2 R)

(b) Predicator-Complement-Predicator Inversion (P-C-P)

Let-type imperative clauses involving predicator-complement-predicator inversion are shown in (30a)-(30b). While the one is essentially rhetorical the other indicates that either the speaker alone, or the speaker in conjunction with the listener or some other referent, is involved.

$$
\begin{array}{llll}
\mathrm{P}-\mathrm{C}_{1} & -\mathrm{P} & \mathrm{C}_{2} & \mathrm{C}_{3}
\end{array}
$$

(30a) $\mid$ Let $\mid$ me |reassure |you |[[that over these four years period the government has started well in so many fronts]].|(PDP Q8 R)

$$
\text { A } \mathrm{P}-\mathrm{C}_{1}-\mathrm{P} \quad \mathrm{C}_{2}
$$

(30b) ||So |let |us |restore | [[that job to our traditional law enforcement agencies]].\|

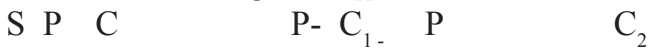

||It |is | their duty.|| ||Let |them |do |it.||(KOWA Q8 C)

(c) Initial Complement (Initial C)

The only instance of initial complement truly exemplifying stylistic motivated inversion has identical H-Type AJGs at C, each immediately followed by a PRG at A, with both groups coordinated phonologically. Fronting the complement and repeating it with the accompanying adjunct was reiterative, serving as philosophical underpin for the position held by the speaker (cf. Millar \& Curie, 1972).

$$
\text { C A }
$$

(30c) $\|$ Consistent $\mid$ with the position of Professor Achebe in his book The Trouble with Nigeria,

$$
\text { C A }
$$

|consistent | with his justification at the Garden City Literary Festival in Port Harcourt,

$\mathrm{S}$ P $\mathrm{C} \quad \mathrm{A}$

it $\mid$ is $\mid$ interesting |[[to know that all ethical intellectuals in Nigeria, no exception, agree that leadership is the bane of development in Nigeria]].||(NCP Q1 R)

\section{The Compound Sentence}

The 168 compound sentences occurred as displayed in Table 6 below, which clearly shows that the two-clause compound sentence was dominant and that none exceeding five clauses occurred.

\section{The two-clause compound sentence}

The two-clause compound sentence was more of declaratives than interrogatives and imperatives. The last two are shown in (32a)-(32b) and (32c).

(32a) $\|(\alpha)$ How do we transmit this power $\|$ and $\|(\alpha)$ how do we distribute this power? ||(AA Q2 S)

(32b) $\|(\alpha)$ What do you expect from your government $\|$ and \|( $\alpha$ ) what do you owe your government?|| (These are the directions in which KOWA would work.)(KOWA Q6 C

(32c) $\|(\alpha)$ Make pure water available to this people in this region ||and then $\|(\alpha)$ improve their infrastructure.||(APA Q3 S)

What seems more common was the coordination of imperative and declarative sentences.

(33a) ||( $\alpha$ Let me admit that some impetus have been given to the agric sector $\|$ and so $\|(\alpha)$ there is visible improvement.||(UPP Q7 R)

(33b) (We must be number one in this world and I can do it.) ||( $\alpha$ ) Send me ||and $\|(\alpha)$ I will go.||(AA Q1 C)

The two-clause compound sentence marked for declara- 
Table 6. Manifestation of the Compound Sentence

\begin{tabular}{lccc}
\hline Subtype & $\begin{array}{c}\text { No. of } \\
\text { sentences }\end{array}$ & Percentage & $\begin{array}{c}\text { No. of } \\
\text { clauses }\end{array}$ \\
\hline Two clauses & 145 & 86.3 & 190 \\
Three clauses & 21 & 21 & 63 \\
Four clauses & 1 & 1 & 4 \\
Five clauses & 1 & 1 & 5 \\
& 168 & & 262 \\
\hline
\end{tabular}

tive indicative mood was distinguished according to whether or not there was an overt marker of coordination and according to the coordinating conjunction involved. Although no statistical count was taken, sentences with coordinators were evidently dominant and the coordinating conjunction was and meaning addition, which also served to provide more information and reinforce that previously given. An excerpt is taken from each theme thus:

(34a) ||$(\alpha)$ I am coming from a background of thirty-nine years of human rights activism $\|$ and $\|(\alpha)$ that is my strength. || |||( $\alpha$ )That's where I am coming from ||and $\|(\alpha)$ that is the yardstick with which my government will be judged.||(UPP Q1 C)

(34b)||( $\alpha$ Nigerians cannot be offered less as we have seen today $\|$ and $\|(\alpha)$ there is no justifiable reason to give Nigerians this sort of treatment over the years.||(HDP Q2 $\mathrm{R})$

(34c) $\|(\alpha)$ So, we are going to put that in place $\|$ and $\|(\alpha)$ we are hopeful that within a short term we'll be able to tackle the problem of bunkering in this country.||(ADC Q3 C)

(34d)||( $\alpha$ )And we said security votes must be tied to only security $\|$ and $\|(\alpha)$ must be accounted for. $\|($ UPP Q4 S)

(34e) $\|(\alpha)$ They need to be given their lives back $\|$ and $\|(\alpha)$ those who have suffered bereavement also need to have their situation ameliorated.||(KOWA Q5 S)

(34f) ||$(\alpha)$ This country has never managed the Tertiary Education Fund the way we are doing $\|$ and $\|(\alpha)$ we can attest to that.||(PDP Q6 S)

$(34 \mathrm{~g})||(\alpha)$ Therefore, agriculture is something that is very serious $\|$ and $\|(\alpha)$ it needs to be taken seriously. ||(UDP Q7 C)

(34h) ||$(\alpha)$ We must consolidate our gains $\|$ and $\|(\alpha)$ move our country forward for our children and grandchildren. ||(PDP Q8 C)

In compound sentences linked by and meaning result the second clause highlighted the logical consequence of the propositional content of the first, which was invariably negative.

(34i)(What we have today is not acceptable.) |||( $\alpha$ )It cannot be centralised $\|$ and $\|(\alpha)$ expect no vandalism as it is going on. ||(HDP Q2 S)

$(34 \mathrm{j}) \|(\alpha)$ Corruption is endemic $\|$ and $\|(\alpha)$ it has eaten deep into the fabric of our society.||(ACPNQ4 R)

$(34 \mathrm{k}) \|(\alpha)$ They have grievances there $\|$ and $\|(\alpha)$ they became restless.||(APA Q5 R)

(341) $\|(\alpha)$ But trouble has come $\|$ and $\|(\alpha)$ we are all bothered.||(UDP Q5 R)

One rare instance of and meaning contrast is (34m) ||$(\alpha)$ We have law courts that are supposed to prosecute \|and $\|(\alpha)$ we have citizens who share in the booty.||(APA Q4R)

Primarily contrastive but reinforced and justified each debater's position on the issues raised. For instance, the speaker in $(35 \mathrm{a})$ claimed he would be quicker at attaining his objectives than the respected sage, while that in $(35 \mathrm{~b})$ contrasted two fundamentally different teacher-education institutions to underscore the need for policy reversal.

(35a) $\|(\alpha)$ Late Chief Awolowo said 'give me three months' $\|b u t\|(\alpha)$ I am asking Nigerians to give me twenty-four hours.||(HDP Q1 C)

(35b) $\|(\alpha)$ Colleges of education may be there, ||but $\|(\alpha)$ colleges of education and teacher training colleges are like oranges and apples. || |||( $\alpha)$ They are both round $\|$ but $\|(\alpha)$ they are not the same. ||$($ UDP Q6 S)

The gap between policy formulation and implementation in three major sectors was highlighted using but thus:

(35c) $\|(\alpha)$ The government has spent so much money on power, $\|$ but $\|(\alpha)$ the effort has been frustrated and sabotaged.||(ACPN Q2 R)

(35d) $\|(\alpha)$ So funding has been made $\|b u t\|(\alpha)$ the equipment is not in place. ||(NCP Q6 R)

(35e) $\|(\alpha)$ Argentina is one of the largest suppliers of beef in the world $\|$ but $\|(\alpha)$ livestock and cattle do not struggle for space with traffic or commuters in that country.||(UPP Q7 R)

A personal resolve to succeed against daunting odds and the superficial attitude toward social maladies like corruption are focussed on in (35f)-(35g).

(35f) $\|(\alpha)$ It's going to take a lot of negotiation $\|$ but $\|(\alpha) \mathrm{I}$ intend to give it a push.||(ADC Q4 S)

$(35 \mathrm{~g}) \| \mid(\alpha)$ Some people react to the symptoms $\|$ but $\|(\alpha)$ very few people know why corruption is described the way it is described.||(UDP Q4 R)

\section{The multiple-clause compound sentence}

The only five-clause compound sentence linked by but occurred as UDP recalled a lecture on Excuses to Criminal Liability where 'Coker is my cousin', used as a contextual metaphor for nepotistic corruption in Nigeria, was cited as one. The bewildered students were told that a defendant confronted with the facts in (36a) had given it as response.

(36a) $\|(\alpha)$ You persecuted permanent secretaries that were corrupt, \|\|$(\alpha)$ you seized properties of people that were corrupt, \|\|$(\alpha)$ you demoted some perm secs, \|\|$(\alpha)$ you even jailed some, ||but $\|(\alpha)$ you did not try Coker.|| (How can I try Coker? Coker is my cousin.)(UDP Q4 R)

The sole four-clause compound sentence employed asyndetic conjunction, which makes each clause's proposition clearer and more distinctive.

(36b) $\|(\alpha)$ We ask the soldiers, \|\|$(\alpha)$ they say they are better equipped, $\|||(\alpha)$ they are now better trained, \|\|$(\alpha)$ they are now better motivated.||(UPP Q8 S) (See (24g) above))

Asyndetic conjunction was also adopted in respect of the two-and three-clause compound sentences. Notice that while (36d) describes a process (36e)-(36f) are repetitive.

(36c) ||$(\alpha)$ Ethical revolution will include us Nigerians, \|\|$(\alpha)$ will involve us Nigerians.||(HDP Q4 R) 
(36d)||( $\alpha$ )So you pluck your jatrova seed, \|\|$(\alpha)$ take it to the nearest extraction point, \|\|$(\alpha)$ get your oil.||(APA Q2 S)

(36e) ||$(\alpha)$ Downstream has to do with refining, \|\|$(\alpha)$ has to do with production of fertiliser, \|\|$(\alpha)$ has to do with petrochemical.||(PDP Q3 S)

(36f) $\|(\alpha)$ They are fixed in Ghana, \|\|$(\alpha)$ they are fixed in the USA, \|\|$(\alpha)$ they are fixed all over the world.||(NCP Q3 S)

Coordination in the three-clause type was by and mainly. While (37a)-(37b) show planned coordination, where the elements are treated as 'naturally linked', $(37 \mathrm{c})$ is the only instance of unplanned coordination that conceives elements as independents found (cf. Wilson, 2008:404).

(37a) $\|(\alpha)$ The economy will grow, $\|(\alpha)$ employment will be created $\|$ and $\|(\alpha)$ Nigeria will be better for it. ||(UPP Q7 S)

(37b) $\|(\alpha)$ And people will begin to live a more descent life, \|\|$(\alpha)$ work harder $\|$ and $\|(\alpha)$ participate in the economy.||(PDP Q4 C)

(37c) $\|(\alpha)$ We will encourage local entrepreneurs to invest in these areas $\|$ and $\|(\alpha)$ deregulate the system $\|$ and $\|(\alpha)$ ensure that Nigerians have over, if you like, 50000 megawatts.||(UDP Q2 C)

In (37d) but highlights the ideological contradiction between policy formulation and policy implementation in $\mathrm{Ni}$ geria's agricultural sector.

(37d) $\mid \|(\alpha)$ We have made fertiliser available, \|\|$(\alpha)$ people are improving on the yield of their farm $\|b u t\|(\alpha)$ at the same time we have livestock.cattle eat up all of these things. ||(UPP Q7 R)

\section{The Complex Sentence}

A total 231 sentences comprising 512 clauses distributed as shown in Table 7 below were structurally complex, but thirty featured beta clauses only. The two-clause complex sentence was the most common, followed by the three-clause subtype. There occurred 446 finite and sixty-six non-finite clauses. Further observations on the complex sentence are based on the finiteness criterion.

\section{The finite clause as beta clause}

Complex sentences with the finite clause as beta clause were further distinguished according to the number of clauses therein. In the two-clause sentence the beta clause either came first or second as (38a)-(38b) and (38c)-(38d) respectively illustrate.

(38a)||( $\beta)$ Secondly, as we speak, \|\|$(\alpha)$ there are over 38000 court cases in Federal High Courts in this country [[waiting for judgement]].||(APA Q4 R)

$(38 b)||(\beta)$ If you plot the graph of poverty in Nigeria and natural revenue, \|\|$(\alpha)$ you are going to see that the higher the revenue the higher the level of poverty.||(NCP Q1 R)

(38c) $\|(\alpha)$ We will not be able to make a quantum leap in agricultural production, ||||$(\beta)$ if we continue with the old farming practices.||(NCP Q1 R)

(38d) ||( $\alpha$ Corruption is the problem of our economy, \|\|$(\beta)$ which we all know.||(AD Q4 R)
The foregoing shows there was no fixed order of occurrence of the elements of structure. What appeared to determine which of alpha or beta was clause-initially were the focus of the message conveyed and each debater's level of linguistic competence. In the corpus analysed the two-clause complex sentence with beta clause as initial was more prominent, attesting to the fact that thematic fronting is not limited to the single clause sentence. In (39a), for instance, the debater appears to emphasise artificial scarcity as the basis for unwholesome behaviour. Similarly, the speakers' intent at emphasising the content of the initial clause in (39b)-(39c) is not in doubt.

(39a) $\|(\beta)$ Where you create scarcity, \|\|$(\alpha)$ people will want to cut corner at all cost. ||(ACPN Q4 S)

$(39 b) \|(\beta)$ If you look at the quantity of crude we are talking about, \|\|$(\alpha)$ it is enormous. ||(ADC Q4R)

$(39 \mathrm{c}) \|(\beta)$ But if we look at it closely, \|\|$(\alpha)$ educational institutions should be left in the hands of those who.know how to run it. ||(UDP Q6 S)

Where the three-clause complex sentence had two beta clauses, the alpha clause was either the median or last clause.

(40a) $\|(\beta)$ Where you subject the farmer to the vagaries of the market situation, \|\|$(\alpha)$ it makes it difficult for them to plan $\|$ and $\|(\beta)$ to get real value for what they have done.||(UDP Q7 R)

$(40 \mathrm{~b}) \|(\beta)$ When a civil servant is not sure that when he is retired he will get a house on his head, \|\|$(\beta)$ when he is retired that his pension will be paid, \|\|$(\alpha)$ he would want to secure his future. $\|(\mathrm{ACPN}$ Q4 R)

In contrast, where two alpha clauses featured, and these were more common, the beta clause was sentence-initially.

(40c) $\|(\beta)$ So, if there are jobs, \|\|$(\alpha)$ nobody will go $\|$ and $\|(\alpha)$ start destroying the pipelines. $\|($ AD Q3 S)

(40d) I||( $\beta$ )If they are so obsolete that they cannot be maintained, \|\|$(\alpha)$ we demolish them $\mid$ and $\|(\alpha)$ rebuild them.|| (NCP Q3 S)

(40e) $\|(\beta)$ Like we have been saying, ||and $\|(\alpha)$ that has been coming up, || ||( $\alpha$ )we have abandoned our groundnut pyramid and so on. ||(KOWA Q7 S)

(40f)||( $\beta$ )When you export raw materials, \|\|$(\alpha)$ you are exporting labour $\mid$ and $\|(\alpha)$ that's the new orientation.||(PDP Q7 C

The four-clause complex sentence featured three alpha or three beta clauses. Interestingly $(40 \mathrm{~g})$ is one of the only

Table 7. Distribution of the complex sentence

\begin{tabular}{lccc}
\hline Subtype & $\begin{array}{c}\text { No. of } \\
\text { sentences }\end{array}$ & Percentage & $\begin{array}{c}\text { No. of } \\
\text { clauses }\end{array}$ \\
\hline One beta clause & 30 & 13 & 30 \\
Two clauses & 139 & 60 & 278 \\
Three clauses & 49 & 21 & 147 \\
Four clauses & 8 & 4 & 32 \\
Five clauses & 5 & 2.2 & 25 \\
& 231 & & 512 \\
\hline
\end{tabular}


two instances of coordination by or seen (See (41n) below). $(40 \mathrm{~g})||(\alpha)$ We must rectify that system, || or $\|(\alpha)$ innovate it,, $\mid$ or $\|(\alpha)$ reorder it, \|\|$(\beta)$ otherwise, we will just be repeating ourselves all the time.||(UDP Q4 S)

$(40 \mathrm{~h}) \|(\beta)$ But because of the quantity and quality of food we are producing, \|\|$(\beta)$ even when the oil prices dropped $\|$ and $\|(\beta)$ the value of the naira dropped a little, $\|$ $\|(\alpha)$ it does not affect the food prices.||(PDP Q7 C)

The five-clause complex sentence is illustrated thus:

(40i) ||$(\beta)$ So, once you are able to tackle the big problem, $\|$ $\|(\beta)$ show example.no matter how highly placed they are. ||and $\|(\beta)$ are brought to book $\|$ and $\|(\beta)$ the international community gives us the support, \|\|$(\alpha)$ a lot of the billions of dollars that we are losing on a daily basis will be channelled back into the economy.||(ADC Q3 C)

\section{The non-finite clause as beta clause}

The complex sentence with the non-finite clause as beta clause primarily exhibited semantic attributes associated with each non-finite form. For instance, where the tonon-finite VBG clause with purpose as meaning was the first element of sentence structure, the debater was able to justifiably identify the direction in which he would go on a given issue. Similarly, the $\mathrm{x}+\mathrm{g}$ suggested on-going actions while some form of completion was associated with the $\mathrm{x}+\mathrm{n}$ form. These interpretations become clearer as the forms are encountered in context.

One feature associated with the two-clause sentence was that where the initial clause was alpha, the beta clause was invariably $x+g$ or $x+n$ non-finite VBG clause as (41a) (41c) and (41d)-(41e) respectively show.

(41a)|||( $\alpha$ )We can't go on complaining, || ||( $\beta)$ looking for solutions for what we know is there living with us.||(HDP Q3 S)

(41b) |||( $\alpha)$ In addition to that we will increase the minimum wage by reducing the maximum wage, \|\|$(\beta)$ thereby compressing the inequality index.||(NCP Q8 S)

(41c) $\|(\alpha)$ We are talking about the total value chain in agriculture, || ||( $\beta)$ bringing manufacturing, processing.||(PDP Q7 S)

(41d)||( $(\alpha)$ So we propose to have our police strengthened, $\mid$ $\|(\beta)$ in fact, reorganised completely.||(HDP Q5 S)

(41e)||( $\alpha$ )So we are getting to that level because we have seen that our economy is so small, \|\|$(\beta)$ compared to the size of the labour force and the population.||(AD Q3 C)

Only rarely did there occur $t o+x+0$ and no $\mathrm{x}+\mathrm{o}$ was seen.

(41f) $\mid \|(\alpha)$ We come back to the issue of security, \|\|$(\beta)$ how to prevent it.||(UPP Q5 S)

Only $\mathrm{x}+\mathrm{g}$ and $t o+\mathrm{x}+\mathrm{o}$ non-finite $\mathrm{VBG}$ clauses featured at sentence initial. The former is illustrated first.

$(41 \mathrm{~g})||(\beta)$ After getting it, \|\|$(\alpha)$ we are not even investing part of it into our economy.||(AD Q3 R)

(41h) ||( $\beta)$ Having said that, \|\|$(\alpha)$ the petroleum industry has to be opened up.||(UPP Q4 S)

(41i)||( $\beta)$ Even starting with the electoral process, \|\|$(\alpha)$ before 2011,Nigerians were not too interested whether they had electoral cards or not.||(PDP Q1 R)
While initial positioning for emphasis can be taken as given, the foregrounding of to-non-finite VBG clause meaning purpose provided additional motivation for listening. This interpretation should be understood against the fact that all sentences occurred in the context of specifying actions to be taken and listeners would want to know precisely what the speakers' intentions were.

(41j)||( $\beta)$ To stamp out corruption, \|\|$(\alpha)$ there must be social security.||(ACPN Q4 S)

$(41 \mathrm{k})||(\beta)$ To solve the problem of power supply in Nigeria, ,| $\|(\alpha)$.we are suggesting full deregulation.||(CPP Q2 S)

(411)||( $\beta)$ For us to seriously tackle corruption, \|\|$(\alpha)$ there is every need that we give it a holistic approach.||(ADC Q4 S)

The beta clauses in the three-clause complex sentences shown below are a mix of finite and non-finite.

(41m) ||$(\alpha)$ We simply have to get to work, \|\|$((\beta)$ using our minds \|and $\|(\beta)$ using our hands. ||(KOWA Q8 S) (41n) $\|(\alpha)$ That is the day you decide where to go, || ||( $\beta)$ whether it's business as usual, || or $\|(\beta)$ to embrace UPP revolutionary agenda.||(UPP Q8 C)

(41o) ||$(\alpha)$ That air will go ||and $\|(\alpha)$ turn the turbine, \|\|$(\beta)$ not gas now turning the turbine.||(APA Q2 S)

In (41p) what looks like a fourth clause is indeed the adjunct of the alpha clause, truncated due to the speaker's eagerness to add the relevant information borne by the beta clause.

(41p) $\|(\alpha-)$ Access to land is another critical thing that we can encourage state governments, \|\|$(\beta)$ because they are in charge, $\|(\beta)$ based on the Land Use Act, \|\|$(-\alpha)[$ to make easier for farmers]]. ||(NCP Q7 R)

Finally, the four-clause and five-clause complex sentences are respectively illustrated in (41q)-(41r). Notice that whereas the beta clauses in the one are all $\mathrm{x}+\mathrm{o}$ non-finite forms the other includes a finite clause.

(41q)|||( $\alpha$ )But the UPP government will begin immediately to equip $\|$ and $\|(\beta)$ decentralise the police, \|\|$(\beta)$ decentralise the security agencies, ||and $\|(\beta)$ get everybody involved in the issue of security.||(UPP Q5 C)

(41r) ||$(\alpha)$ But at that point in time the government will be taking the lead, \|\|$(\beta)$ dictating $\|$ and $\|(\beta)$ calling the shot, $\|$ $\|(\beta)$ because, before now, such gestures have been given to these trouble fomenters $\|$ and $\|(\alpha)$ they did not change.||(CPP Q5 C)

\section{The Minor Sentence}

The minor sentence represents what Millar and Currie (1972:44) describe as omission of elements of clause structure, majorly the predicator and the subject. Two-thirds (110 or $66 \%$ ) of the 147 minor sentences occurred without VBGs while one-third (37 or 34 per cent) occurred with VBGs as in (42a)-(42b) respectively.
A
A
$\mathrm{A}_{2}$
C

(42a)||Very simply.||.||How| many times?||. ||Basic things.||. $\mathrm{S} / \mathrm{C} \quad \mathrm{C}$

||One teacher.|| ||Very simple.||.
$\mathrm{A}_{1} \quad \mathrm{~A}_{2} \quad \mathrm{~A}_{3}$
$\mathrm{A}_{1}$
$\mathrm{A}_{2}$
$\mathrm{A}_{1} \quad \mathrm{~A}_{2}$

||So| back |to corruption, || back | to leadership,|| back| to bad governance.||(NCP Q6 RSC) 
(42b)(We also have to look at our borders. Our borders are so porous.)

$$
\text { C A }
$$

||Porous |in the sense [[that by now on a daily basis we can't even keep, give account of

the number of foreigners coming into our country]].||(CPP Q5 S)

Minor clauses with and without VBGs are shown together in (42c).

(42c)(We have a fantastic country, Nigeria.) $\mathrm{C}$

||The most populous black nation in the whole world.|| $\mid \mathrm{A}$ country [ [ that is almost 170

$\mathrm{C}$

million people]].|| ||A country [[that is almost twenty times the size of Singapore]].\|. C

A

\|Beautiful country.| With everything [[you can think of]].\|(AA Q1 R)

As the examples show, the contextually inferable missing elements amplify the impact of the sentence since their absence does not subtract the meaning which is not already implicit (cf. Millar \& Currie, 1972:44). Some more minor sentences are identified as follows:

(42d) No more to hunger in Nigeria (AA Q1) Fellow Nigerians (UDP Q1; AA Q1)

Very critical (NCP Q7) Kidnapping, insurgency and all of that (HDP Q5)

The non-monetary (KOWA Q4) Opportunities for all (AA Q4) No (UPP Q1)

Out of the ten local governments of Borno State, three remaining (PDP Q5)

\section{Collapsed Sentences}

It must be unambiguously stated that this brief consideration of collapsed sentences is not an analysis of errors; rather, it is an attempt to objectively account for all occurring sentences in the corpus. Forty-three sentences comprising thirty-seven complex and six simple subtypes collapsed. They consist of fifty-seven clauses including sixteen non-finite ones. Thirty syntactically understood complex sentences occurred as beta clauses only because the obligatory alpha clause was unrealised due to a combination of factors, including natural language dynamism. Although syntactically defective they nevertheless contributed toward achieving debaters' goals. For instance, (43a) collapsed but its textual function of justifying the action to be taken inferable from the preceding sentence (enclosed) remains largely unaffected.

(43a)(And we said security votes must be tied to only security matters and must be accounted for.)

$\|(\beta)$ Because we know state governments in this country who use pliable state assemblies to appropriate

for themselves security votes that are even more than their state recorded expenditure, ||(UPP Q4 S)

The next sentence is syntactically interesting because, of its five beta clauses, only the first occurred with a marker of subordination. Its syntactic defect notwithstanding, the listener should be able to agree with the speaker that corruption underlies insecurity and agitations in Nigeria.

(43b) $\|(\beta)$ When people know how much oil per barrel is sold, $\|$

$\|(\beta)$ they know how much production Nigeria makes because they are public numbers,

$\|(\beta)$ they imagine the revenue, $\|$

$\|(\beta)$ they hear a budget every year||and

$\|(\beta)$ they don't see it. $\|$

(Everybody doesn't have the same moral threshold. It is not an excuse but these are the real issues we need to deal with before we bring in this other issue of motivating our soldiers. And you cannot motivate with corruption. Corruption universally de-motivates.)(NCP Q5 C)

Not all the collapsed sentences made much sense though. Consider these:

(43c) ||$(\alpha)$ And I have over the years,

$\|(\beta)$ having travelled all over the world for the past twenty-four years, to all the continent of the

world up till this minute.||(AA Q1 R)

(43d) $\|(\alpha)$ And of course the FAO recently gave us a, recognised us, at least reducing this

basic, basic hunger by fifty per cent, as one of the MDG goals. ||(PDP Q7 S)

(43e)||| I discovered that the lapses in Nigerian leadership require not only the experience of someone who has

started very young in administration and who has not been found wanting $\|$ (APA Q1 R)

(43f) ||$(\beta)$ And until something is done urgently to redress the situation, $\|$

(In the last thirty, forty years there was nothing like oil theft or oil bunkering).|||

( $\beta$ )Until we urgently do something.||

(If we have refineries established all over the country, there is market.) (ACPN Q3 R C)

\section{Defining Features of the Sentence in Political Texts}

Before now the sentence in political texts had not been described with this much detail as attempted here. So the question that logically follows is: What does this analysis of Nigeria's 2015 Presidential Debate say about the characterising features of the sentence in political texts? This question can only be answered summarily in this final section on data presentation and discussion of results. It must however be noted that speakers addressed an audience that was both small and immediate, wide and remote, at once; responded to questions on diverse subjects posed by moderators who are largely journalists; and, managed to impress their listeners and possibly woo them to their sides. To achieve their goals and adequately and unambiguously convey their ideas and feelings, debaters employed strategies that saw a 92 per cent dominance of the major sentence over its minor sentence counterpart out of a 1876-sentence corpus, for instance. That minor sentences occurred at all attests to the fact that the dynamics of natural language cannot be ignored even in very serious language use situations such as the 2015 Presidential Debate beamed life to a world audience. It is not known what the average length of sentence in political texts and in- 
deed everyday language use is. But, while the recorded mean of13.6 w/s may be indicative of both individual linguistic competence and oratorical style, its marked disparity with Bellova's (2012) findings suggests that even within political texts, period and genre differences may account for differences in sentence length. Some debaters' responses were characterised by very short sentences $(9.85 \mathrm{w} / \mathrm{s})$ and others by relatively long ones $(20.03 \mathrm{w} / \mathrm{s})$ and this was regardless of sentence type.

How frequently structurally simple, compound and complex sentences occur in everyday language use situation, or, in a given text type, is, again, unknown. However, the revelation of a proportion of seventy-seven, ten and thirteen respectively makes the simple sentence dominant and the compound slightly less recurring than the complex subtype. Clause density was higher with the complex sentence than with the compound sentence at 2.22 and 1.6 clauses per sentence respectively. The fact that these varied according to speaker and according to thematic dimension definitely leads to the conclusion that subject matter, mediate goal such as specifying actions to be taken, speaker's linguistic repertoire, and style of discourse may jointly explain the patterns found. Thus it cannot be logically argued that debaters who used more complex and compound sentences were better able to articulate their points, or, presented same more succinctly, convincingly and effectively, than those for whom the use of the simple sentence may be said to represent an idiolect. There are two reasons: One, the combined frequency of compound and complex sentences was only 30 per cent of that of simple. Two, outside the syntactically plain kernel sentence which constitutes 59 per cent (Many were manifestly complex in their own right, with rankshifted groups and clauses as elements of group structure.), the rest exhibited diverse forms of internal syntactic complexity characterised by rankshifting of clauses to function as elements of clause structure and multiplicity, mobility and inversion of clause structure elements. Since it was not uncommon to find structurally complex groups as elements of clause structure it cannot be claimed that the texts were characterised by syntactic simplicity. It would seem that sentence types were selected in proportions that suited each speaker and the theme addressed.

Seventeen syntactic variants of the structurally simple sentence were isolated and only one lies within the eight generable by the $(\mathrm{S}) \mathrm{P}(\mathrm{C})(\mathrm{A})$ clause structure formula handled as kernel sentences in this study. There was a total absence of the $\|\mathrm{P}\|$ and $\|\mathrm{P}\| \mathrm{A} \|$ and a paucity of $\|\mathrm{P} \mid \mathrm{C}\|$ and $\|$ $\mathrm{P}\|\mathrm{C}\| \mathrm{A} \|$ structural variants, suggesting that, with the probable exception of the let-type imperative, clauses marked for imperative mood were a rarity because of the situational context. The other sixteen variants were almost evenly distributed between simple sentences with rankshifted clauses as elements of clause structure and those with their structures radically affected by situation-induced clausal processes of multiplicity, mobility and inversion. Implicit in these are syntactic complexity at another level of description and debaters' grammatical sophistication. An under- lying desire to place a greater emphasis on certain issues raised, and pack in as much information as are relevant and possible in order to drive home a point, was clearly evident in the choice and frequency of the different patterns of the simple sentence seen, including the positioning of adjuncts outside their normal end slot, which affected 10 per cent. These observations are equally true of even the structurally compound and complex sentences particularly in terms of clause density, clause positioning, and clause coordination. With the former, conjunctions were deliberately chosen to enable debaters connect related facts and highlight their attitude towards the contents of the proposition; and, in the case of the latter, the focus of attention determined which of the obligatory and optional elements of sentence structure was thematically fronted for maximum effect.

\section{CONCLUSION}

What this paper set out to do was to analyse sentence pattern and usage in the Presidential Debate held in Nigeria in 2015 as a study of syntactic structure in political texts. Employing an improved version of the systemic grammatical model as analytical tool, the study identified and accounted for all occurring sentences in the corpus and found the major sentence dominant over its minor sentence counterpart. It classified all the major sentences into simple, compound and complex subtypes, and revealed that not only was the structurally simple sentence over three times more frequently used than the structurally compound and complex sentences combined, the choice of sentence type or its syntactic variant, length of sentence and distribution, varied markedly according to the debates' eight themes, speakers' mediate goals, and debaters' grammatical sophistication. Finally, the study demonstrated how debaters strategically used the sentence to convince listeners to vote for them, noting that the positioning of clauses or clause structure elements, including which of alpha or beta was clause-initially, was ruled by the focus of the message conveyed, for instance. Since details of the outcome have been elaborately given above it only remains to consider some implications.

This analysis has proven that there are levels of simplicity and degrees of complexity in sentence structure and that an otherwise simple sentence can indeed manifest forms of complexity at its various elements of structure. This challenges us when we say we are studying or teaching the language that people actually use, but we employ a model that lacks the capacity to account for what people actually say. The systemic grammatical model chosen has its limitations as already seen, but our adoption of the upgraded $(\mathrm{S}) \mathrm{P}(\mathrm{C})(\mathrm{A})$ clause structure formula, where situation-categories' motivated textual functions were added, together with the three primary sentence types of simple, compound and complex recognised, has enabled us to comprehensively account for all occurring sentences in the corpus. The choice of the sentence is underscored by the need to shift focus from the strands, which sometimes results in fragmentation, apart from the sentence being the primary 
unit of communication. This study has demonstrated that syntactic analysis at the level of the sentence is essential to a full and proper understanding of political texts (cf. van Leeuwen, 2012). If any new insights have been gained into the structure of the English sentence generally and the sentence in political texts particularly, following the analysis of Nigeria's 2015 Presidential Debate undertaken here, then the goals of the study would have been met and this should be consolidated.

\section{REFERENCES}

Abdel-Moety, D. M. (2015). American political discourse as manifested in Hilary Clinton's interviews: A critical discourse approach. English Linguistics Research. 4(1) doi:10.5430/elr.v4n1p1;URL: https://elr.doi.org105430/ elr,v4n1p1.

Adejare, O. (Forthcoming). Natural language linguistics: Text, form and situation.

Adejare, R.A. (2013). The English verbal group: Its form, meaning and function. Saarbrücken: LAP Lambert Academic Publishing.

Adejare, R. A. (2018). The central pronouns in Nigeria's 2015 Presidential Debate: A grammatical analysis. International Journal of English Linguistics. 8(2), April 2018, pp56-72; Available: URL: http://doi.org/10.5539/ ijelv8n2p56. December 2017.

Adejare, R A. \& Adejare, O. (2006). Tertiary English grammar (2nd ed). Lagos: DIFAMO Books.

Akinwotu, S. A. (2013). A speech act analysis of the acceptance of nomination speeches of Chief Obafemi Awolowo and Chief M.K.O. Abiola. English Linguistics Research, Available:. URL: http://dx.doi.org/10.5430/ elr.v2n1p43-51.

Astrero, E. T. (2017). Linguistic analysis of social relation in a political and religious discourse. Presented at the DLSU Research Congress 2017. De La alle University, Manila, Philippines, June 22, 2017. Available:. www. disu.edu.pb/conferences/disu-research.congress-proceedings/LCS-1002pdf.

Ayeomoni, M.O. (2001). Style in Nigerian political speeches. Ife Studies in English Language. Vol.5, September 2001, pp117-128.

Bellovả, H. (2012). Political crisis speeches of American presidents: 1861-2011. Master's Thesis, Masarryic University, Bryno. Available: info.searchnil.com/ sarmg2.b/search/web? fcoid $=41.7 \& \&$ fcop=topnn \&fpid=2\&com_next

Berry, M. (1975). Introduction to systemic linguistics I: Structure and systems. London: B. T. Batsford.

Bloor, T.\& Bloor, M. (1990). The functional analysis of English: A Hallidayan approach. London: Arnold.

Butler, C. S.(1979).Recent work in systemic linguistics. Language Teaching and Linguistics: Abstracts 12-1. Cambridge: Cambridge University Press, pp 71-89.

Cienki, A. (2009). Spoken language framing in political discourse. Workshop paper prepared for Joint ECPR Joint Sessions. Lisbon, Portugal, 14-19 April 2009. Work- shop 19: Studying the Political through Frame Analysis. Available: https://ecpr.eu/filestore/Paper Proposal/187c5cda-fd7d-499e-b6ca-cd518820fd17pdf.

Coulthard, M.\& Montgomery, M.M.(1985).Originating a description. In M. Coulthard \& M. M. Montgomery (eds). Studies in discourse analysis. London: Routledge \& Kegan Paul, pp1-12.

Eggins, S. (2004). An introduction to functional linguistics (2nd ed.). London: Continuum.

Firth, J.R.(1951). Modes of meaning. Papers in linguistics. (Rpt. from Essays and Studies. The English Association), pp 190-215.

Halliday, M.A.K.(1961). Categories of the theory of grammar. Word. (Rpt. as Bobbs-Merill Series, No Language 36), 17(3). 241-92

Halliday, M. A. K.(1966).Some notes on 'deep' grammar. Journal of Linguistics 2.,pp57-67.

Halliday, M. A. K.(1970). Language structure and language function. In J. Lyons (ed.). New horizons in linguistics. Middlesex: Penguin. pp140-65.

Halliday, M. A. K.(1985). An introduction to functional grammar. London: Edward Arnold.

Halliday, M.A.K.\& Matthiessen, C. M.I.M. (2004). An introduction to functional grammar. London: Arnold.

Halliday, M.A.K., Mclntosh, A. \& Strevens, P.(1964). The linguistic sciences and language teaching. London: Longman.

Halliday, M.A.K. \& Webster, J. J. (2008).Text linguistics: The how and why of meaning. London: Equinox.

Harris, R. (1990). The integrationist critique of orthodox linguistics. In M.P. Jordan (ed.). The Sixteenth LACUS forum 1989. Illinois: Linguistic Association of Canada and the United States, pp 63-77.

Huddleston, R. (1988). Constituency, multi-functionality and grammaticalization in Halliday's functional grammar. Journal of Linguistics. 24 (1), pp137-174. Available: http://wwwjstor.org/stable/4115924.

Kenhekanova, K. K. (2012). Linguistic features of political discourse. Mediterranean Journal of Social Sciences. Available: A http://dx.doi:.org/10.5901/mjss. 6(62), p192.

Millar, R. \& Currie, I. (1972). The language of prose. London: Heinemann Educational Books Ltd.

Morley, G.D. (1985). An introduction to systemic grammar. London: McMillan.

NEDG Presidential Debate (2015). 1st session, 12 00pm, size 258 MB. 2nd session.3.00pm-5.00pm, size, 295 MB, length 01:38:11, 22 March 2015. Available: wwwyoutube.com; https://youtu.be/MGwkZr3 S81.

Opeibi, O. B. (2010). Language, globalisation and democratic governance: English in Nigeria's political discourse. In O. Okoro (ed.). Nigerian English in sociolinguistic perspectives: linguistic and literary paradigms. Lagos: Pumark Nigeria Ltd, pp241-260.

Quirk, R., Greenbaum, S., Leech, G., Svartvik, J. (1985). A comprehensive grammar of the English language. London: Longman.

Saussure, F.de (1916). A course in general linguistics. Trans. 
Wade Baskin. ed. Charles Bally and Albert Sechehaye. Intro. Jonathan Culler. Glasgow: Fontana/Collins, 1974. Van Dijk,T. A. (1997). What is political discourse analysis? Available: http://www.discourses.org. pp 11-52.

Van Leeuwen, M. (2012). Rhetorical effects of grammar: Critical approaches to discourse analysis across disci- plines. http://cadaad.net/journal, 5(2), pp88-101. Wilson, J.(2005). Political discourse (Chapter 20). In D. Schiffin, D. Tannen \& H. Hamilton (eds.). The handbook of discourse analysis. Oxford: Blackwell Publishers Ltd. E-version: 14 Jan.2008. http: www//doi. org/10.1002/9780470753460.ch21. 